\title{
نصوص العهدة العمرية بين المُحَدَثين والمؤرخين (تحليل ومقارنة)
}

\author{
رَمَضَان إسنحَاقَ الزَّيَّان \\ أستاذ مشارك في الحديث الشريف وعلوهه- قسم الدراسات الإسلامية \\ جامعة الأقصى- غزة- فلسطين \\ ri.alzayan@alaqsa.edu.ps
}

قبول البحث: 2021/10/23

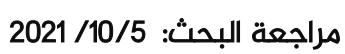

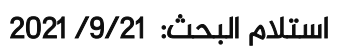

DOI: https://doi.org/10.31559/SIS2021.6.2.1

(c) (1) This file is licensed under a Creative Commons Attribution 4.0 International 


\title{
نصهوص العهدة العمرية بين المُحَدَّثين والمؤرخين (تحليل ومقارنة)
}

\author{
رَمَضَنَان إسنحَحَاق الزََّّان \\ أستاذ مشارك في الحديث الشريف وعلومه- قسم الدراسات الإسلامية \\ جامعة الأقصى- غزة- فلسطين \\ ri.alzayan@alaqsa.edu.ps
}

DOI: https://doi.org/10.31559/SIS2021.6.2.1 2021/10/23 2021/9/21 مراجعة البحث: 2021/10/5 قبول البحث البحث:

يتناول هذا البحث تحليل نصيوص العهدة العمرية عند علماء أهل الحديث الشريف وعلماء التاريخ والمقارنة بين جهودهما.

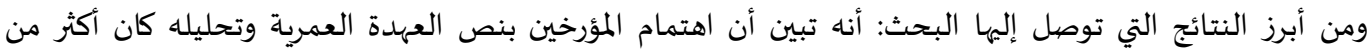
المُحَدَثين، وتبين أيضاً أن أكثر نص اهتم به المؤرخون في التحليل كان نص الإمام الطبري، وكذلك تبين أن العهدة العمرية تمثل

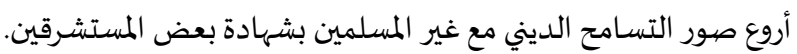

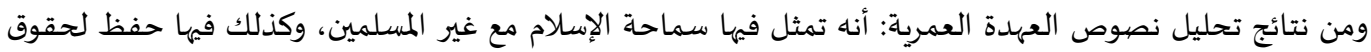
الغير، وفيها مراعاة لشرائع الآخرين واحترامها لخصوصياتهم، وفي العهدة محافظة على العهود والمواثيق، وكذلك تأكيدها لعدم الإكراه في الدخول في دين الإسلام. ومن التأثيرات الإيجابية للعهدة العمرية أنها أثرت في المدائن الأخرى، فعندما ترامت أنباؤها إلى أهل الرملة تطاولت أعناقهم لكي يعقدوا مع أمير المؤمنين عمر -رضي الله عنه- معاهدة مثلها، وكذلك فعل مثلهم أهله أهل اللد. الكلمات المفتاحية: العهدة العمرية؛ تحليل نصوص؛ مقارنة؛ المُحَدَّثين؛ المؤرخين.

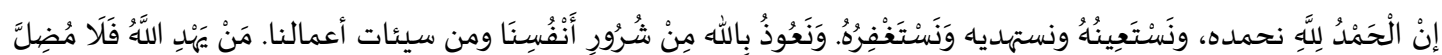

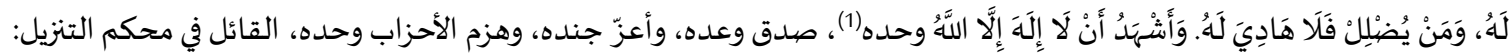

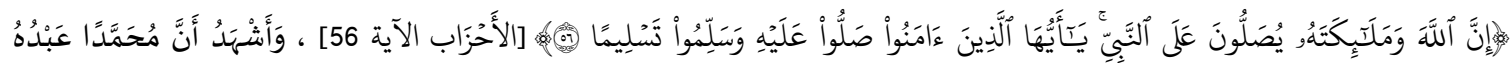

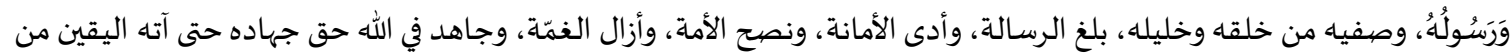

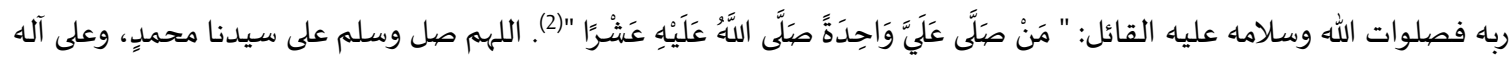
وأصحاباه، ومن تبعهم بإحسان إلى يوم الدين.

فإن موضيوع هذا البحث يتناول تحليل نَصّ العهدة العمريّة بين المُحَدّثين والمؤرخين فيما اصطيح العلماء على تسميته بالعهدة العمرية حيث عهد الأمان الذي كتبه الخليفة الراشد الفاروق عمر بن الخطاب رضي الله عناه لنصارى القدس الشريف -أهل إيلياء في ذاك الزمان - عندما تم الاتفاق على فتحها صلحاً حين وافقوا على دفع الجزية ودخولهم في ذمة المسلمين وما ترتب عليه من حقوق الته 
وواجبات على كلا الطرفين، حيث سجل هذا العهد أنصع صفحات الإسلام في تعامله مع مخالفيه رغم أههم كانوا في موقح الهزيمة

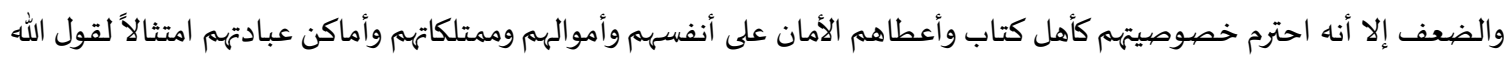

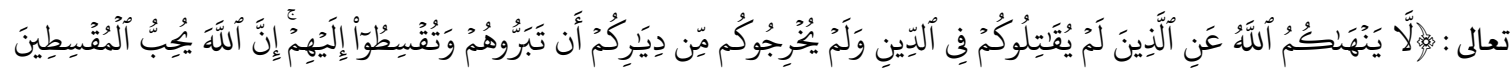

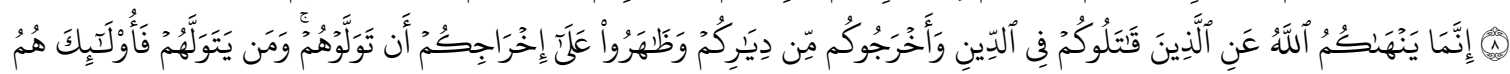

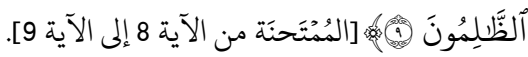

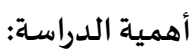
ولهذا الموضوع أهمية كبيرة في زمن يدعي فيه أعداء الإسلام أن دين السماحة واليسر والمحبة هو دين يدعو للإرهاب والقتل،

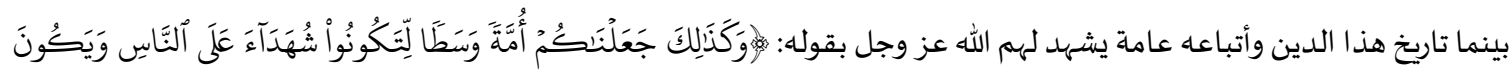

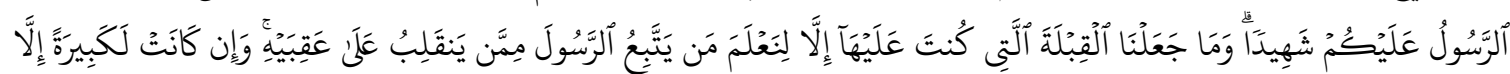

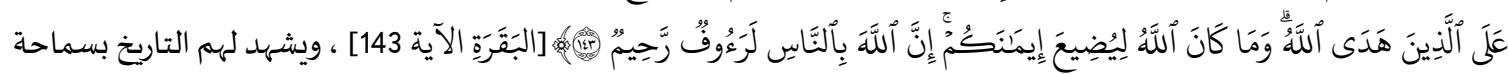

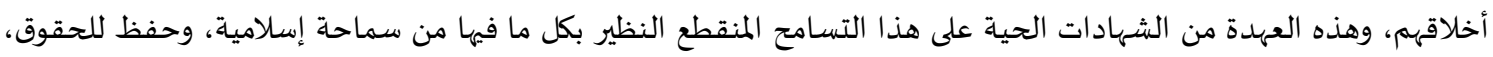
ومراعاة واحترام لشرائع الآخرين، ومحافظة على الشهات العهود على هذا المواثيق، وعدم الإكراه في الدين.

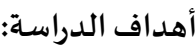
وتهدف الدراسة إلى إبراز حقيقة العهدة العمرية التي انبرى بعض المشككين (3) في وجودها كحدث في تاريخ المسلمين مما دفههم إلى مهاجمتها دون بحث علمي أصيل، والمقارنة بين جهود علماء الحديث وعلماء التاريخ في تحليل نصوص التهائ العهدي العهدة العمرية.

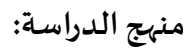

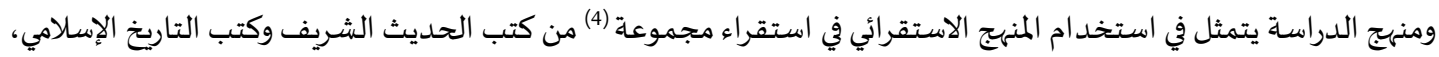

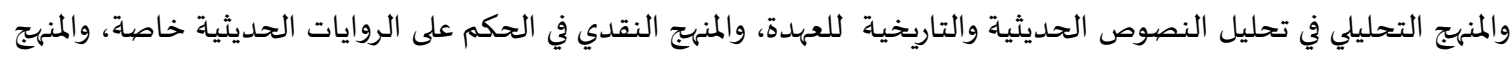
المقارن في مقارنة جهود المُحِدِّين في تحليل نص المهائ العهدة مع بعضهم ثم مع جهود المؤرخين.

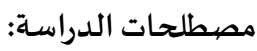

ومصططاتحات عنوان الدراسة تتمثل في:

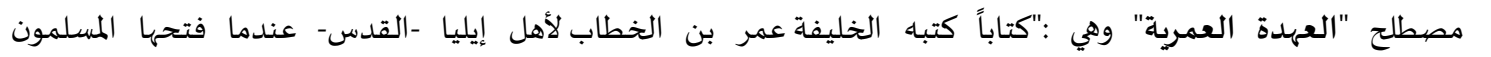

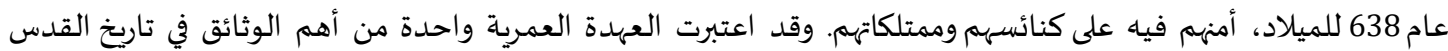

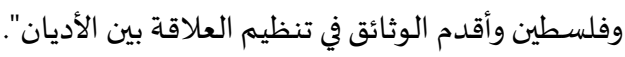

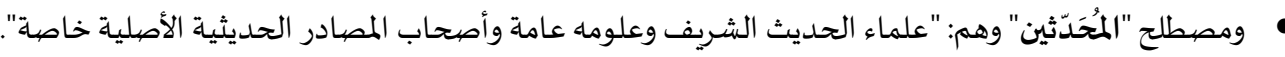
و ومصطلح "المؤرخين"، وهم: "العلماء الذين لهم جهود في كتابة أحداث التاريخ ويشتغلون بنقله ونقده وتحليله والاستفادة منهاه".

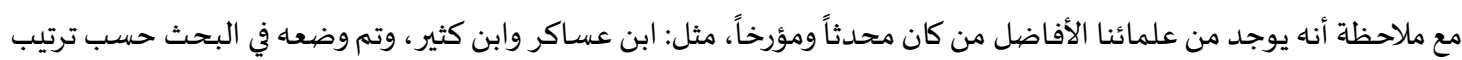

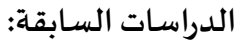

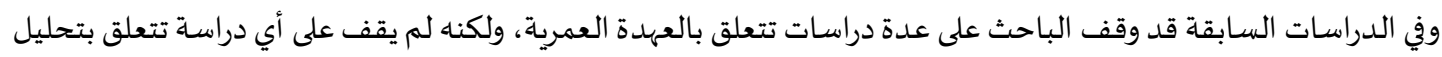
نصوصها لا عند المحدثين ولا عند المؤرخين فضلاً عن المقارنة بين الفريقين، ومن أهم هذه الدراسات المات المات ما يأتي:

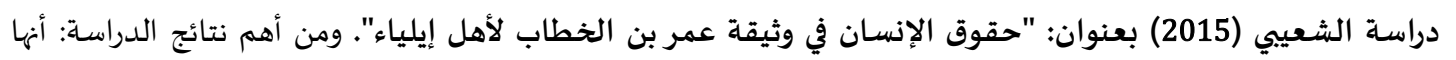

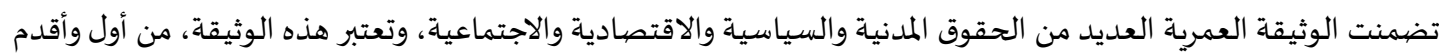

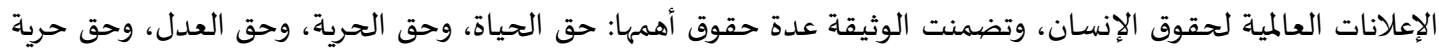
الاعتقاد، وحق الأمن، وحق تقرير المصير السياسي، وحق التملك، وحق التكافل الاجتماعي. 
دراسة فارس (2010)."قراءة في العهدة العمرية"، وقد اهتم بالجانب اللغوي لنص العهدة برواية الإمام الطبري، وقد كان من

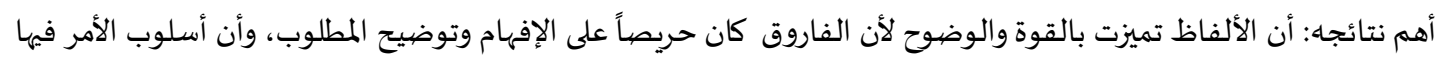

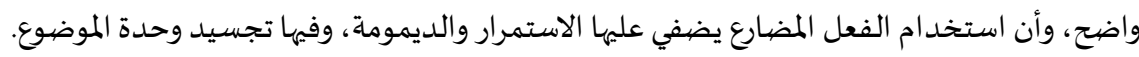

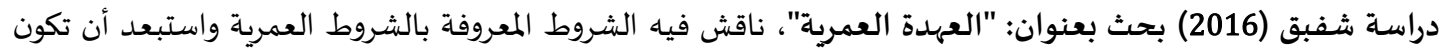

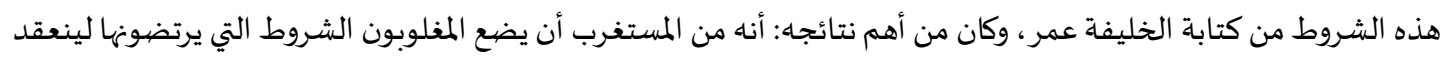

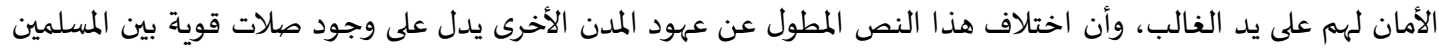

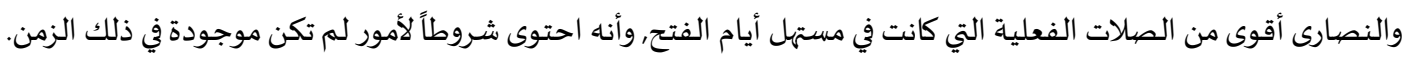

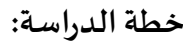

يتكون البحث من مقدمة وثلاثة مباحث وخاتمة وقائمة للمصادر والمراجح.

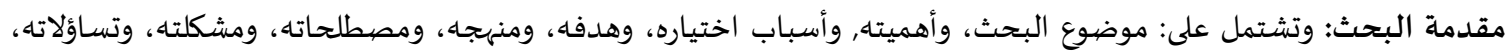

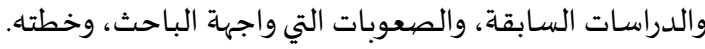
المبحث الأول: "مدخل لدراسة نصوص العهاتدة العمرية" وفيه: أولاً: تسمية العهدة العمرية. ثانياً : كتابة العهدة العمرية وفتح مدينة القدس. ثالثاً : إثبات العهدة العمرية بين المُحَدَثين والمؤرخين. رابعاً : مقارنة بين نصوص العهدة العمرية.

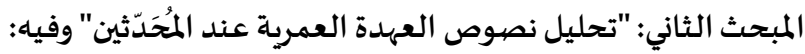
تمهيد: روايات العهدة العمرية عند المُحَدَّثين. أولاً: تحليل نص الإمام أحمد في كتابه المسند. ثانياً: تحليل نص الإمام ابن حبان في كتابه الثقات.

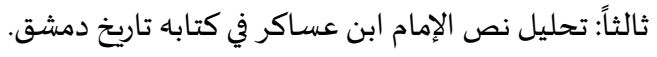

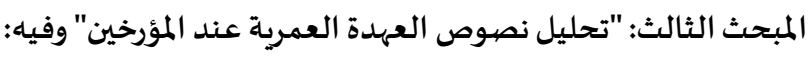
تمهيد: روايات العهدة العمرية عند المؤرخين. أولاً: تحليل نص خليفة بن خياط.

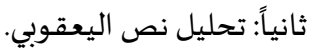
ثالثاً: تحليل نص الطبري. رابعاً: تحليل نص المطهر بن طاهر. خامساً: تحليل نص الأزدي. سادساً: تحليل نص ابن كثير. خاتمة البحث: تشتمل على نتائج البحث وتوصياتها

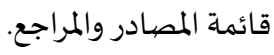

\section{المبحث الأول: مدخل لدراسة نصهوص العهدة العمرية}

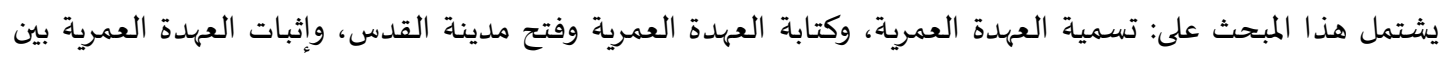
المحدثين والمؤرخين، ثم الختام بمقارنة بين نصوص العهدية لعهدة العمرية.

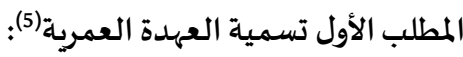

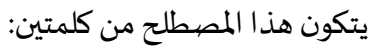


الأولى: "العهدة "، وهي مأخوذة من العهد وهو الأمان. وقد استخدمت كلمة " العهد " في القرآن الكريم بلفظها ثماني مرات، في

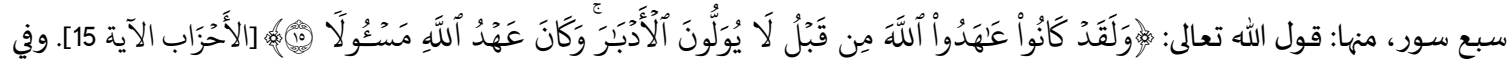

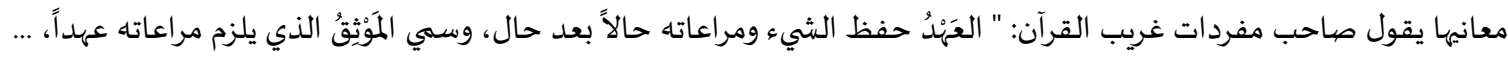

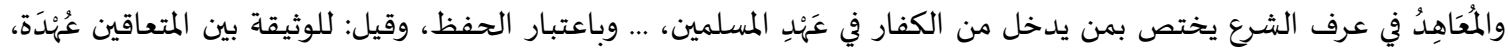

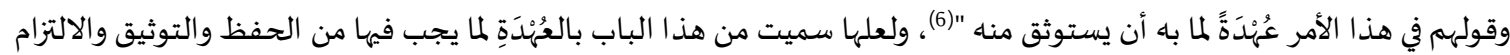

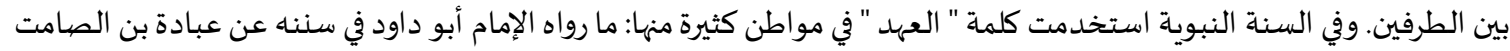

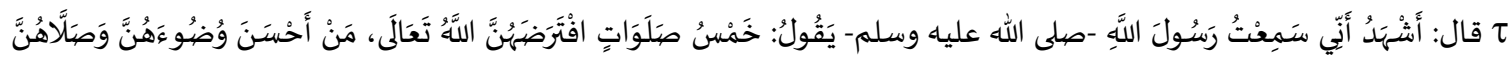

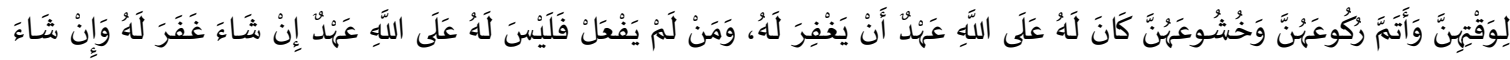

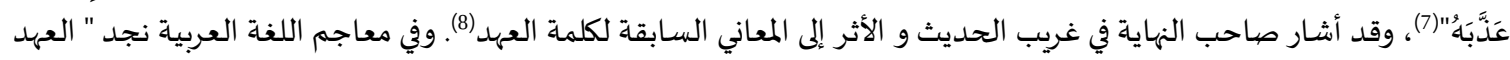

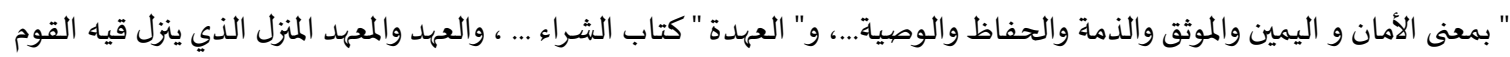

إذا انتأوا عنه ورجعوا إليه (9).

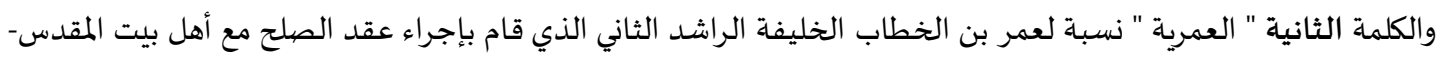

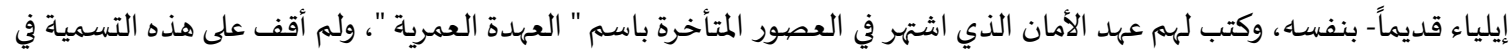

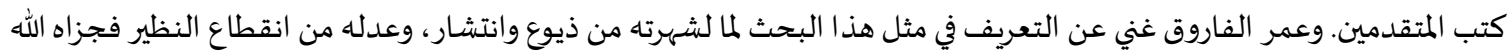

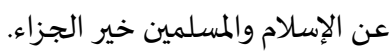

المطلب الثاني: كتابة العهدة العمرية وفتح بيت المقدس (10):

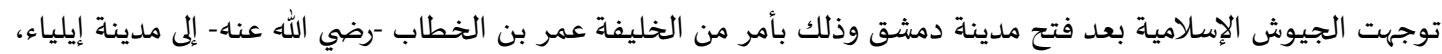

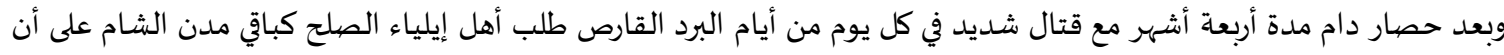

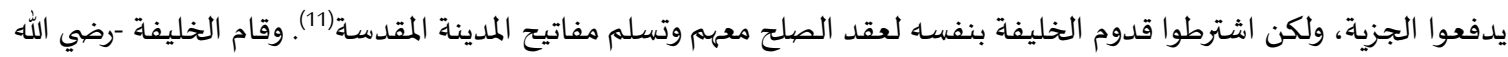

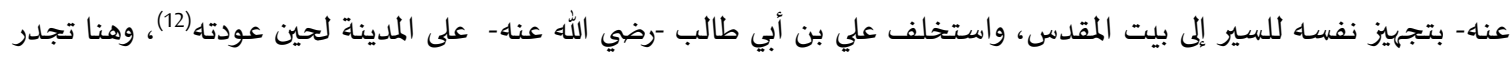

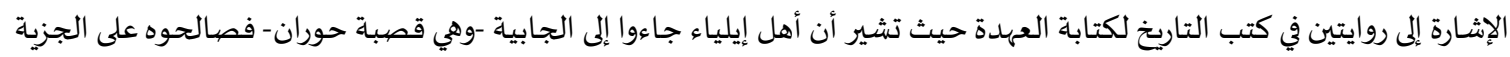

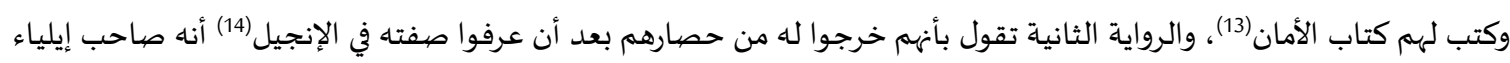

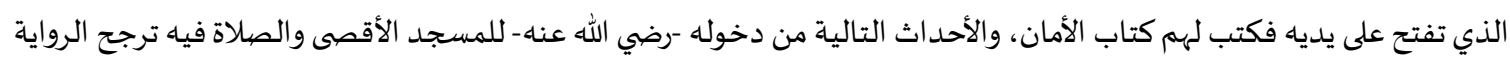
الثانية والله أعلم.

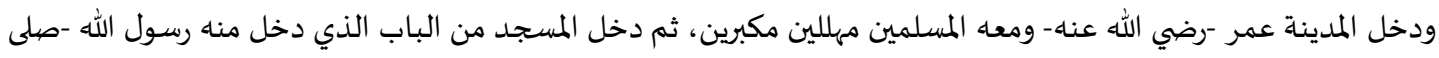

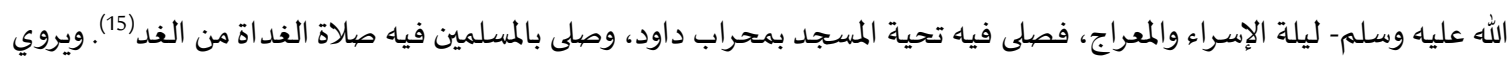

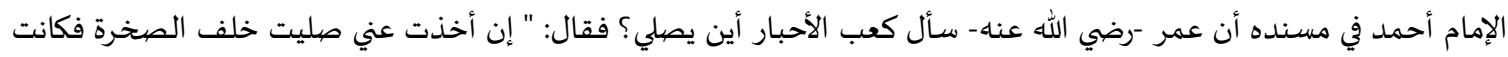

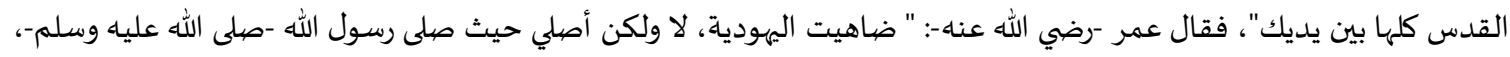

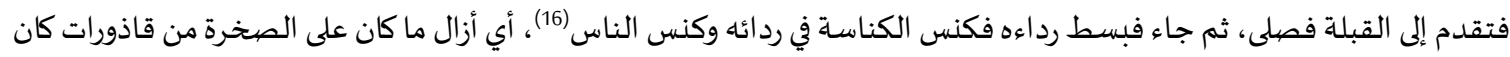

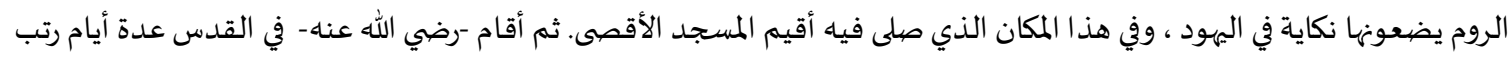

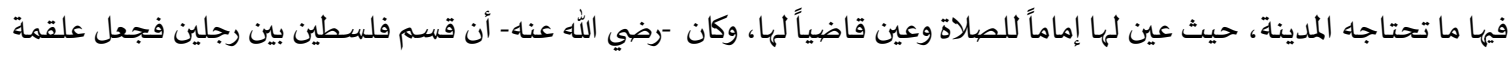

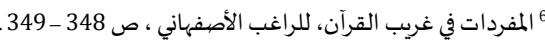

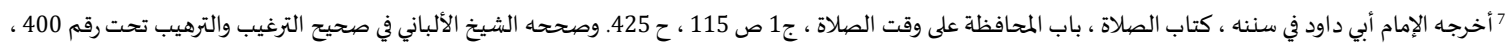
وهو كما قال.

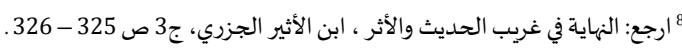

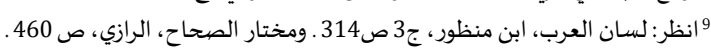

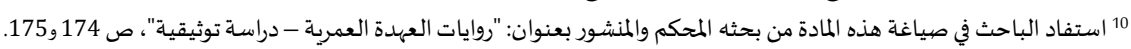

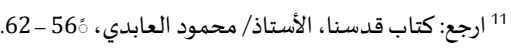

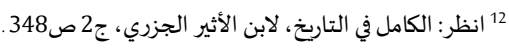

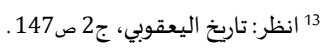

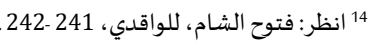

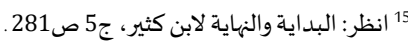
16 مسند الإمام أحمد، ج1 ص38. 
بن حكيم -رضي الله عنه- على نصفها وأنزله الرملة، وجعل علقمة بن محمد -رضي الله عنه- على نصفها وأنزله إيلياء(17)، وهكذا

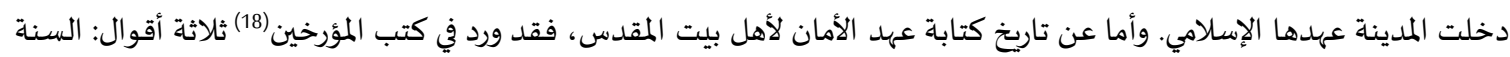

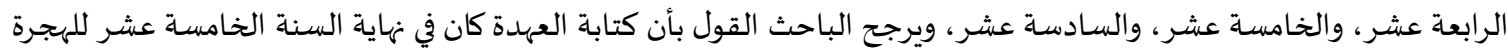

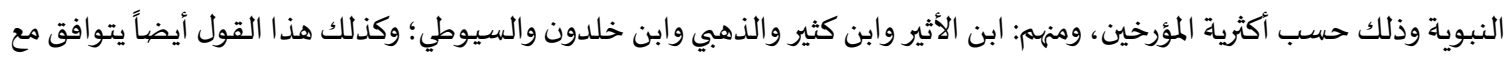

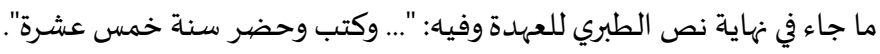

المطلب الثالث: إثبات العهدة العمرية بين المحدثين والمؤرخين(19):

من الغريب أن المصادر الإسلامية الأولى لم تشر إلى ذلك العهد، فأول مصددر إسلامي أشار إليه هو اليعقوبي، ثم أورده من بعده

ابن البطريق وابن الجوزي، والطبري، ومجير الدين العليمي(20).

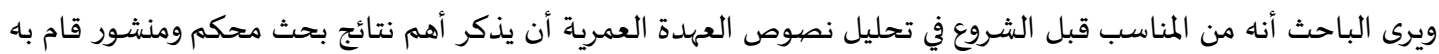

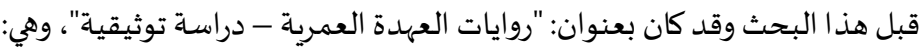

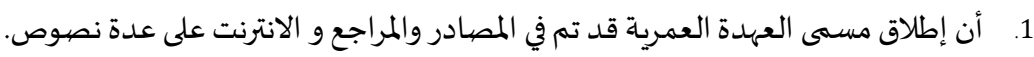

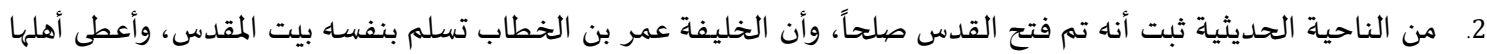

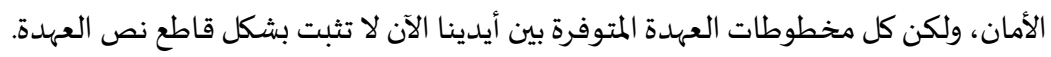
3. من الناحية التاريخية كان نص الطبري أفضل ماهو هو متوفر بين أيدينا.

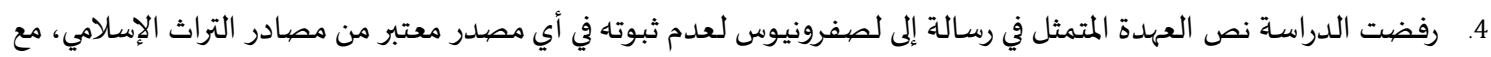
ظهور علامات الوضع عليه.

5. فرقت الدراسة بين العهدة العمرية والشروط العمرية التي يتناولها الفقهاء في كتههم في موضوع أهل الذمة، واعتبرت جميع الأسانيد التي وصلت بها هذه الشروط إلينا أسـانيد ضعيفة بسبب الانقطاع فيها.

6. أكد البحث على أن المكان الذي كتبت فيه العهدة العمرية هو منطقة الجابية بالقرب من دمشق، وكان ذلك في نهاية السنة الخامسـة عشرة للهجرة.

المطلب الر ابع: مقارنة بين نصيوص العهدة العمرية:

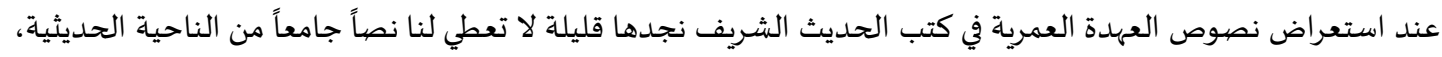
فهي تثبت أنه قد تم فتح القدس صلحاً، وأن الخليفة عمر بن الخطاب -رضي الله عند- تسلم بنفسها بيت المقدس، وأعطى أهلها

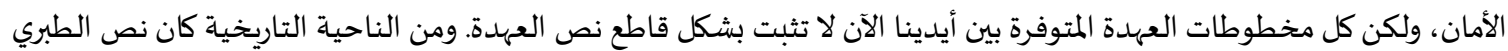
أفضل ما هو متوفر بين أيدينا. وهناك نص لا يمكن اعتباره ثابتاً وقد أورده صياحب كتاب وثائق فلسطين من العهدة العمرية إلى وعد بلفور (21)، تحت وثيقة رقم

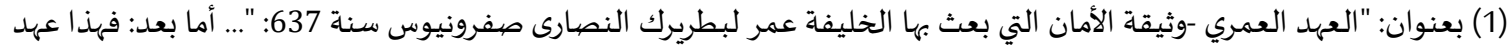

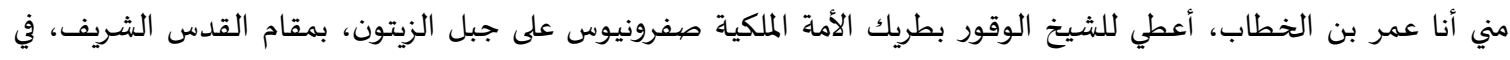

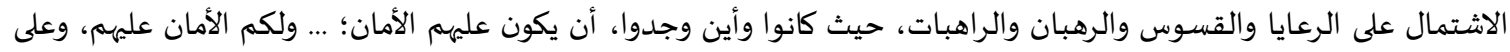

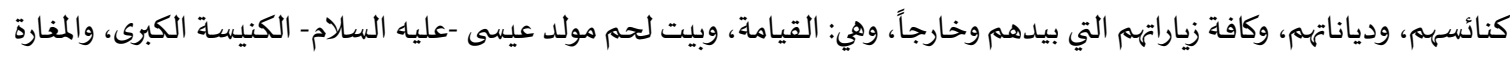
ذات الثلاثة أبواب قبلي وشمالي وغربي، وبقية أجناس النصارى الموجودين هناك وهم: الكرج، ... والموارنة تابعين للبطريرك المذكور،

إنظر : المنتظم في تاريخ الملوك والأمم، لابن الجوزي، ج3 ص112.

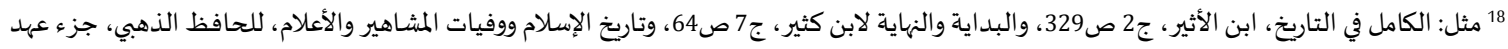

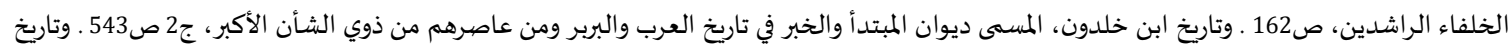

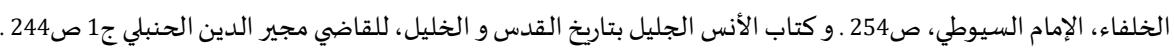

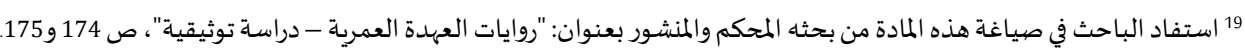

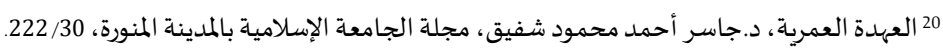

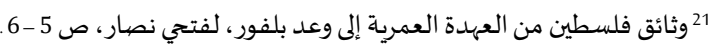


ويكون متقدماً عليهم؛ لأنهم أعطوا من حضرة النبي الكريم والحبيب المرسل من الله (22)، وشرفوا بختم يده الكريمة، وأمروا بالنظر

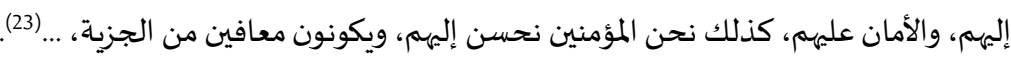
وهذه الوثيقة لا تحتاج إلى كبير عناء لنقضها واثبات أنها موضوعة -مكذوبة- على عمر بن الخطاب -رضي الله عنه-، وقد ورد فيها فيها

تمييز بعض طوائف النصارى على بعض، ثم إسقاط الجزية عن بعضها في حق المسلمين، وتقديمها إلى البطريرك ..." (24). وقد اتضح أن هناك فرق بين العهدة العمرية والشروط العمرية التي يتناولها الفقهاء في كتبهم في موضوع أهل الهل الذمة، واعتبرت

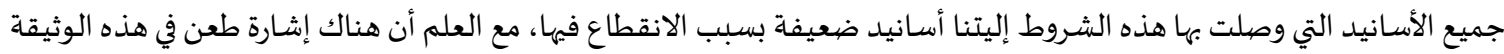

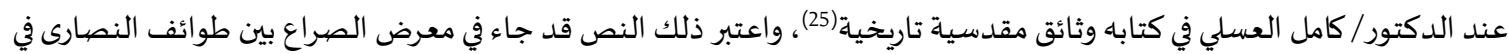
العصور الماضية. وعليه يجب أن نحذر كل الحذر من الوقوع في إثبات نص قطعي للعهدة قبل التأكد بكل الوسائل من ثبوته.

\section{المبحث الثاني: تحليل نصهوص العهدة العمرية عند المُحَحَدثين}

يشتمل هذا المبحث على تمهيد يتضمن روايات العهدة العمرية عند المُحَدَّثين، ثم الشروع في تحليل نصيوصها عندهم، وقد كانت

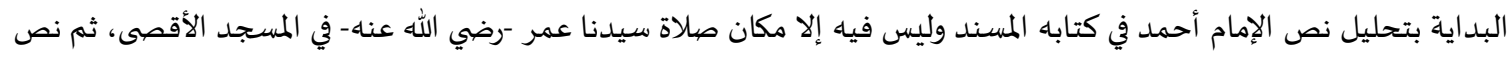
ابن حبان في كتابه الثقات لأنه أكمل نص عند المحدثين يذكر العهدة، وختام المبحث بتحليل نص عند الإمام ابن عساكر في كتابه

تاريخ دمشق.

تمهيد: رو ايات العهدة العمرية عند المححدثين: رغم أن كتب الحديث الشريف سجلت أغلب ما حدث في العهد النبوي وعهد الخلفاء الراشدين بأسانيد من مصنفيها وحتى

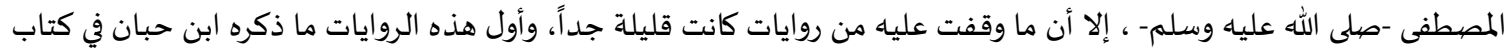

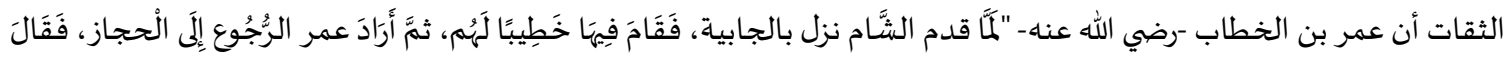

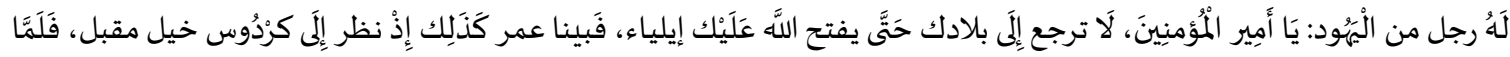

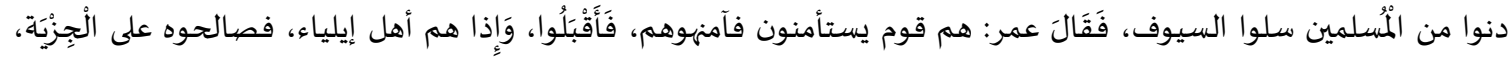

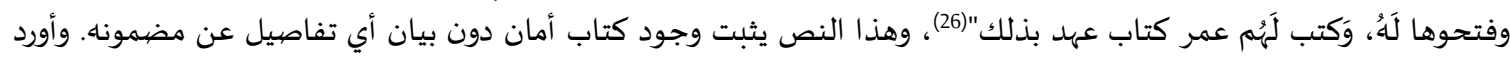

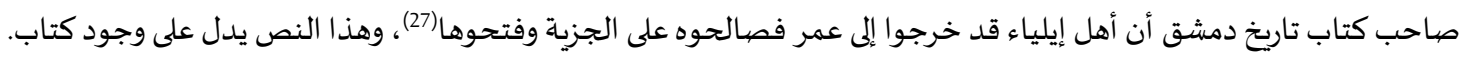
وقد روى الإمام أحمد في مسنده قصة سؤال كعب -رضي الله عنه- عن الصلاة في المسجد الأقصىى، وهي تثبت مضيمون هذه إلهاء

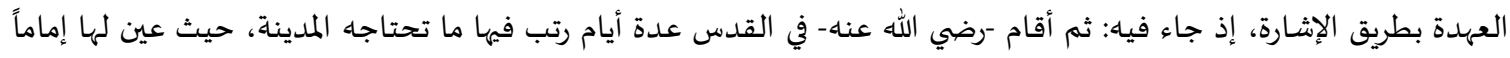

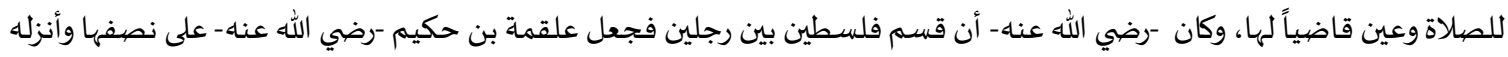
الرملة، وجعل علقمة بن محمد -رضي الله عنه- على نصفها وأنزله إيلياء.

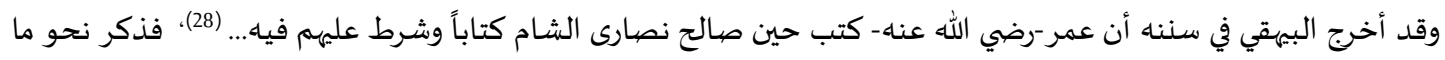
ذكر عبد الله بن الإمام أحمد، مع خلاف يسير في ألفاظه.

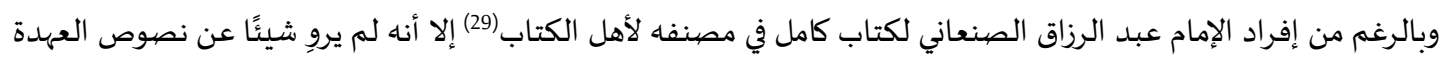

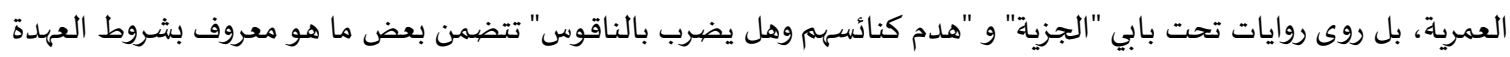
العمرية.

المطلب الأول: تحليل نص الإمام أحمد في كتابه المسند (تمكَ

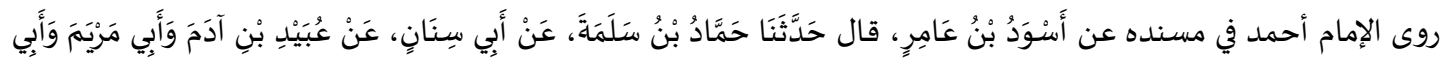
22 لعل الإشارة هنا إلى وثيقة عهد من النبي محمد صلى الله عليه وسلم لهم ، وهي وثيقة موضوعة -مكذوبة - كما أشار صاحب كتاب وثائق مقدسية تاريخية، د. كامل العسلي ، ص

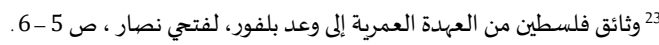

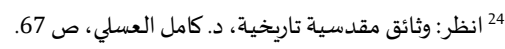

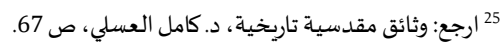

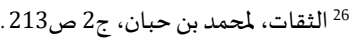

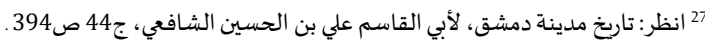

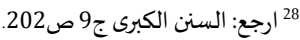
29 ارجع: مصنف عبد الرزاق الصنعاني، ج6 ص ص 3 - 20 


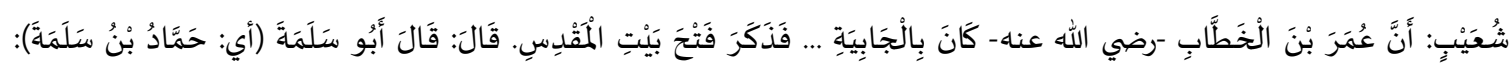

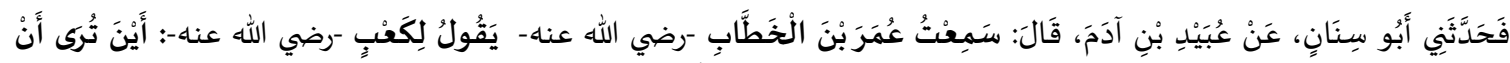

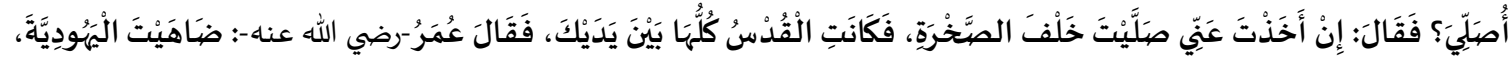

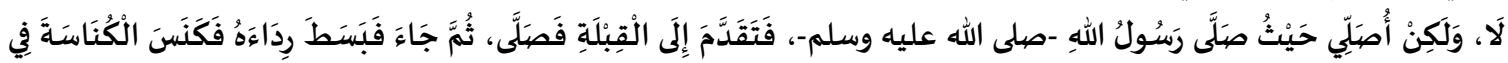

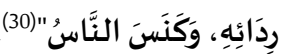

وعند تحليل هذا النص نقف على النقاط الآتية:

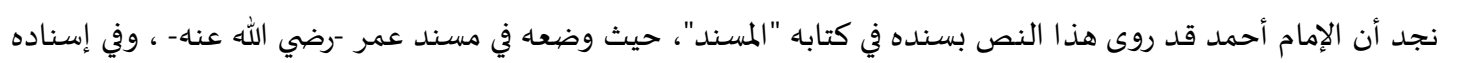

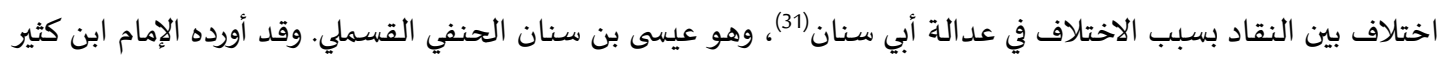

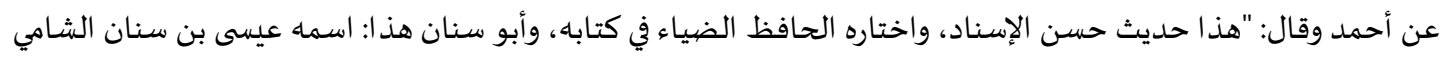

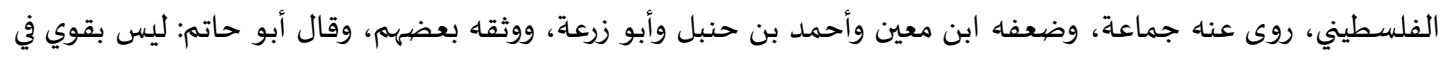

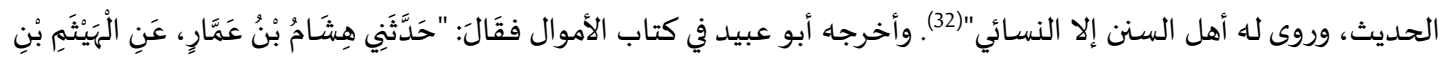

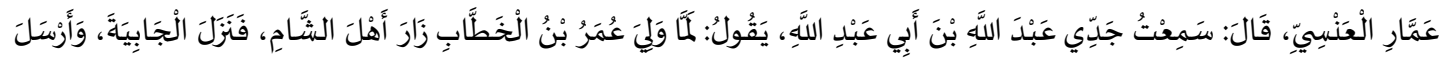

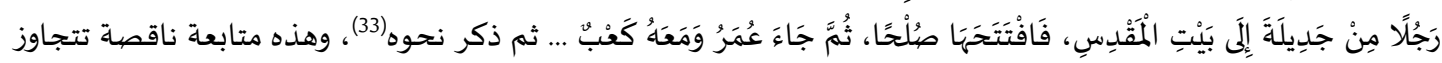

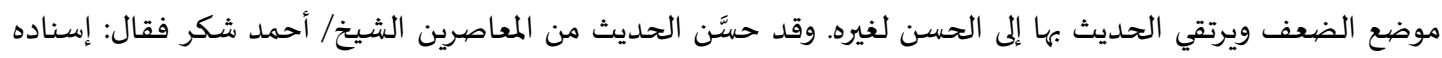

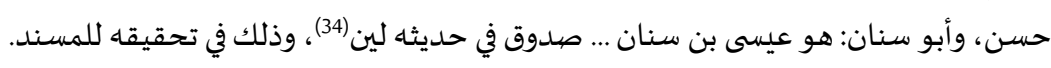
خلاصة القول في الحكم على إسناد الحديث: أنه حسن لغيرن.

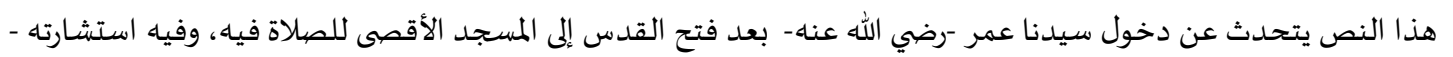

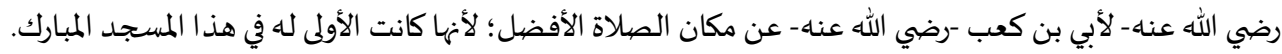

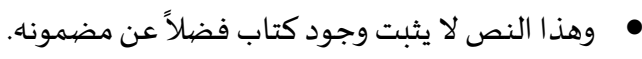

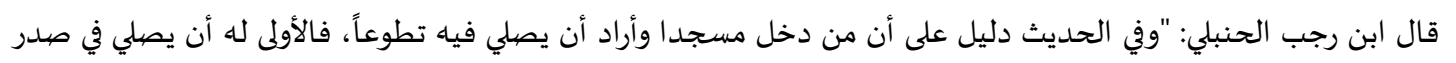
المسجد، لا عند بابه" (35).

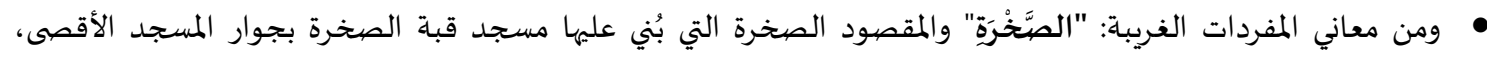

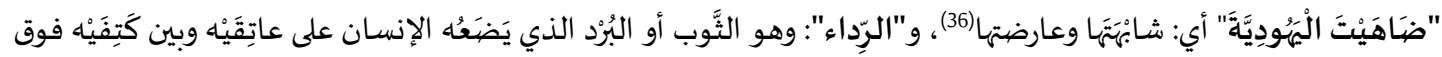
ثيابه (37).

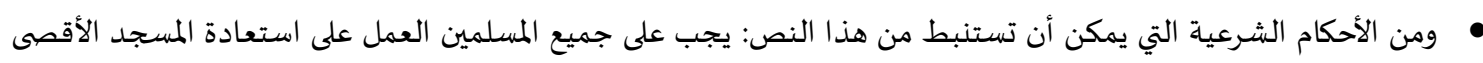

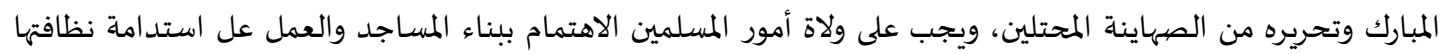

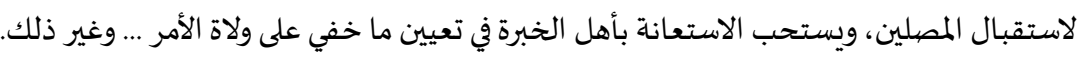

المطلب الثاني: تحليل نص ابن حبان في كتابه الثقات (ت 354هـ):

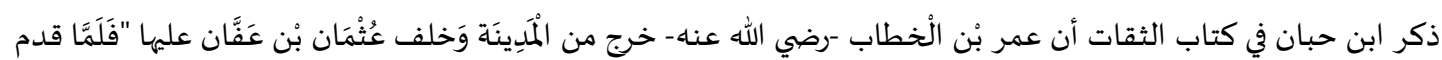

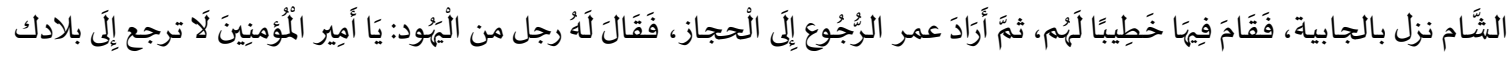

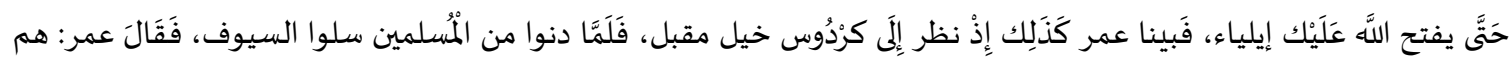

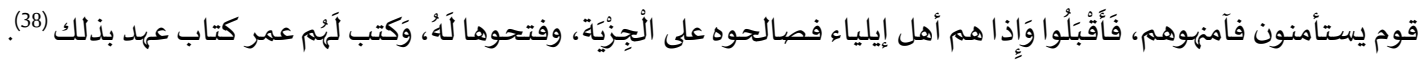
30 رواه الإمام أحمد في مسنده، في مسند عمر -رضي الله عنه- ، ح261، طبعة مؤسسة الرسالة، ج1 ص370، وقال المحقق: إسناده ضعيف لضعف أبي سنان، وهو عيسى بن سنان الحنفي القسملي، وهو كما قال.

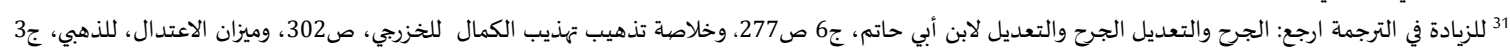

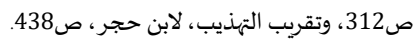

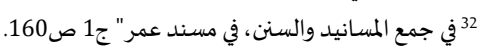

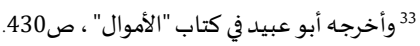

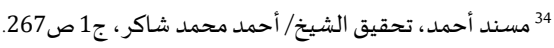

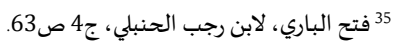

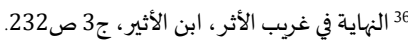

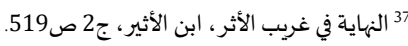
إنقات، لابن حبان، ج2 ص213. 
وعند تحليل هذا النص نقف على النقاط الآتية:

قد ذكر الإمام ابن حبان هذا النص في كتاب الثقات، وهو كتاب خصصيه للترجمة للرواة الثقات عنده، وقد أورد هذا النص تحت عنوان كبير: "في السيرة"، وعنوان أصغر "ذكر وصف رسول الله -صلى الله عليه وسلم-"، وقد بدأ الكتابة بذكر إسناد بدأه

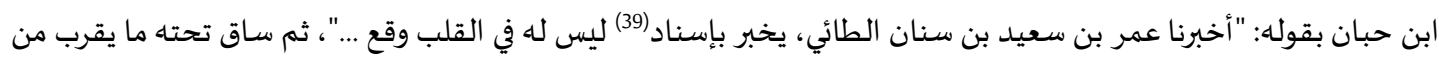

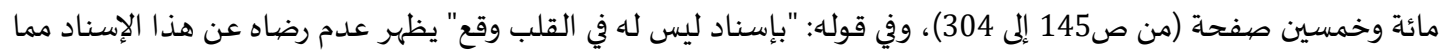

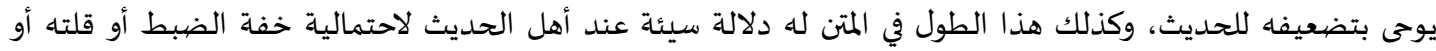

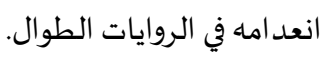
انفرد بإخراج هذا الحديث الطويل من بين كتب السنة ابن حبان في كتابيه الثقات بهذا الإسناد، وكتابه السيرة النبوية وأخبار

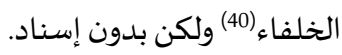
الحكم على إسناد الحديث: أنه ضعيف، حيث يلاحظ الناظر المتخصص بسهولة ضعف هذاد المها الإسناد في قول ابن حبان:" بإسناد ليس لله في القلب وقع"، وابهام راوي في قوله: " حدثنا رجل من بنى تميم من ولد أبى هالة". وهذا النص يثبت وجود كتاب دون بيان أي تفاصيل عن مضيمونه.

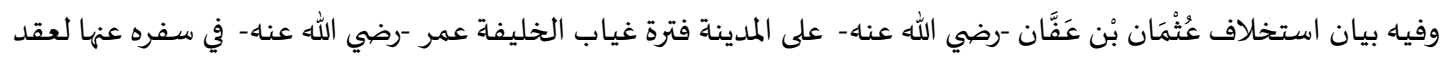
الصلح مع أهل الشام عامة أو أهل إيلياء خاصة،، وذلك فياه ضرورة عدم ترك فراغ في الحكم حتى لا تحدث أضرار للعباد أو

وفيه أن أهل القدس هم الذين جاءوا للصلح مع أمير المؤمنين عمر -رضي الله عنه- ، وليس هو من قدم لهم حسب طلبهم في

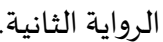

وفيه أن مكان كتابة العهدة كان في منطقة الجابية بالقرب من دمشق وليس على أبواب مدينة القدس كما هو في الرواية الثانية.

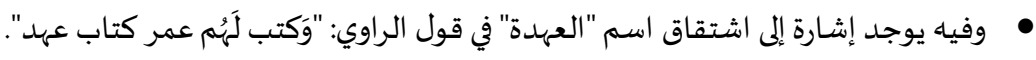
ومن معاني المفردات الغريبة: "الجابية" بكسر الباء وياء مخففة، أصلها في اللغة الحوض الذي يجبى فياء الماء للإبل، وهي قرية

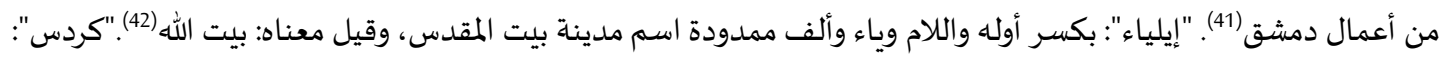

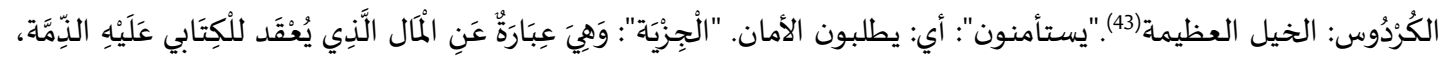

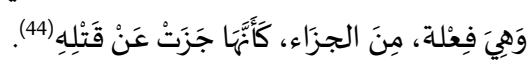
ومن الأحكام الشرعية التي يمكن أن تستنبط من هذا النص: يجب على الإمام توجياه الرعية لما فيه الصواب وإيقافهم قبل

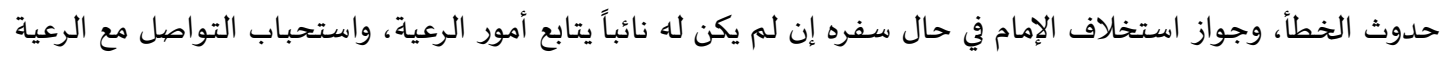
بالخطب وغيرها، وجواز عقد الصلح وكتابة العهود والمواثيق، وجواز تخيير أهل الذمة في البقاء على دينهم مع دفع الجزية...

وغيرها.

المطلب الثالث: تحليل نص ابن عساكر في كتابه تاريخ دمشق (ت571هـ):

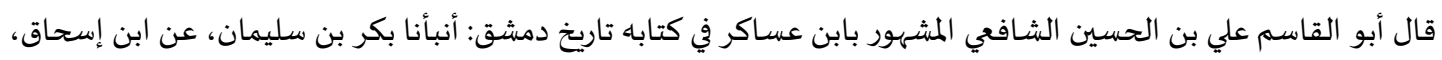

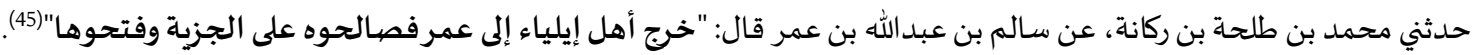
وعند تحليل هذا النص نقف على النقاط الآتياة: • نجد أن الإمام أبا القاسم علي بن الحسن بن هبة الله بن عبد الله الشافعي المشهور بابن عسـاكر قد ذكر هذا النص في كتابه

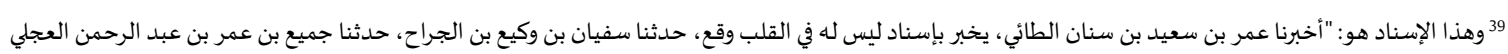

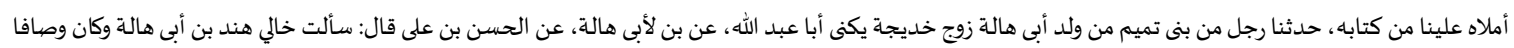

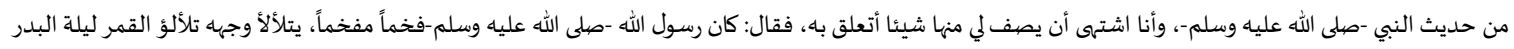

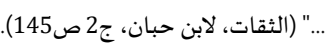

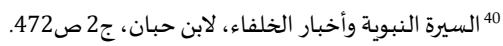

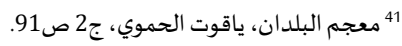

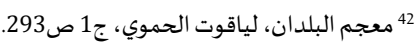

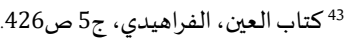


"تاريخ مدينة دمشق وذكر فضلها وتسمية من حلها من الأماثل"، وهو من مجموعة كتب التراجم والطبقات، وقد وضع هذا

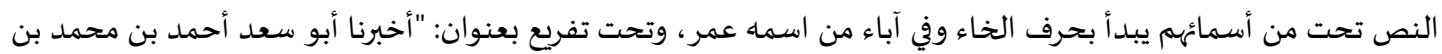

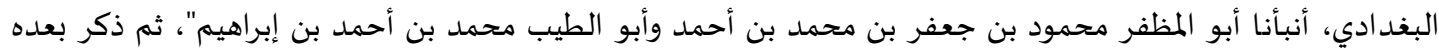

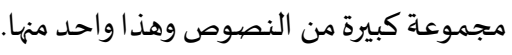

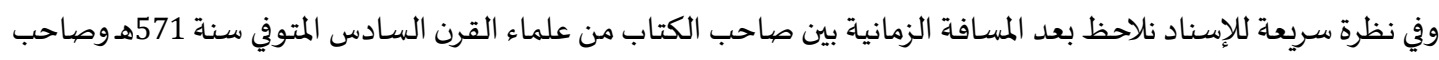

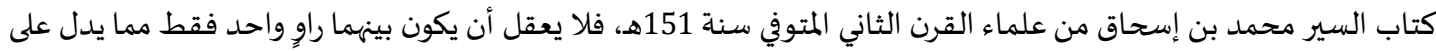
انقطاع واضح في السند. وذكر ابن خياط في تاريخه هذا الأثر بلفظه، وبنفس الإسناد عن بَكْرِ عَنِ ابْنِ إِسنحَاق (46)، نجد أن بكر بن سليمان البصري

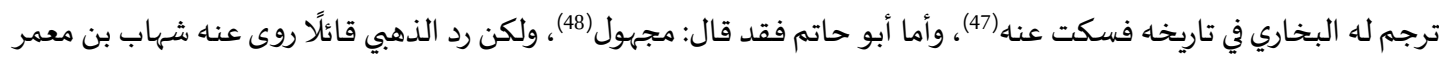
وخليفة بن خياط ولا بأس به إن شاء الله تعالى (49)، وقال الحافظ ابن حجر في اللهاهـ اللسان عن هذا الإسناد: لا بأس باء (50). خلاصة القول في الحكم على إسناد الحديث: أنه ضعيف ضعفاً يسيراً، ويمكن أن يرتقي للحسن لغيره. وهذا النص لا يثبت وجود كتاب كتبه لأمير المؤمنين عمر -رضي الله عنه- لأهل إيلياء.

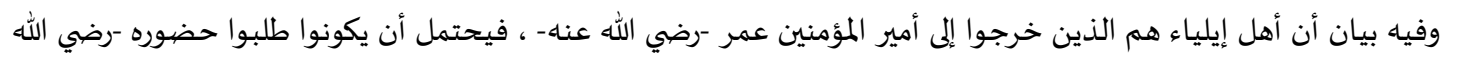

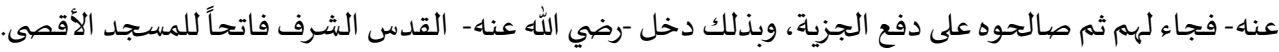
ومن معاني المفردات الغريبة: "شخص": الشُّخوص: السير من بلد إلى بلد"(51)، وتقدم معنى: "إيلياء": اسم لمدئه المدينة القدس.

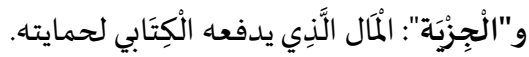
ومن الأحكام الشرعية التي يمكن أن تستنبط من هذا النص: يجوزئ أخذا الجزية من أهل الكتاب إذا لم يحاربوا المسلمين وقبلوا الدخول ذمة المسلمين والعيش كمواطنين في الدولة الإسلامية، يجوز حصار المحاربين من غير المسلمين حتى ينزلوا لحكم

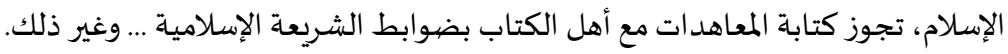

\section{المبحث الثالث: تحليل نصهوص العهدة العمرية عند المؤرخين}

يشتمل هذا المبحث على تمهيد يتضمن روايات العهدة العمرية عند المؤرخين، ثم الشروع في تحليل نصيوص العهدة العمرية

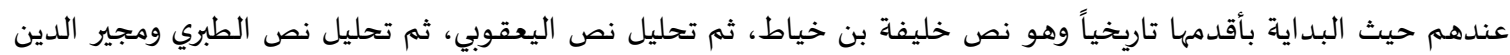

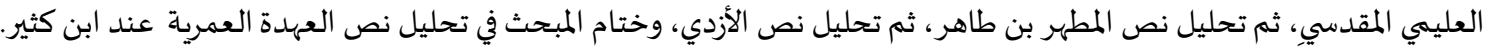
تمهيد: رو ايات العهدة العمرية عند المؤرخين:

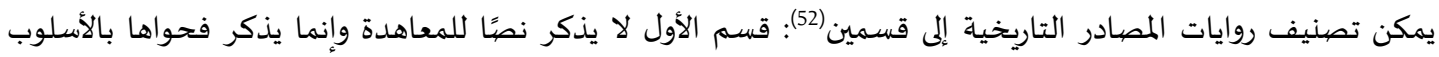
السردي، وقسم الآخر يذكر نص المعاهدة. القسم الأول: يعتبر من أسبق روايات هذا القسم ما رواه الواقدي، والبلاذري ثم ابن الأثير وابن كثير، فقد روى الأول روايتين بشأن الصلح، وروى الثاني أيضًا روايتين. والقسم الثاني: تنقسم روايات هذا القسم إلى ثلاث فئات، الأولى منها: روت مصادرها نصوص التهائ المعاهدة بين عمر بن الخطاب،

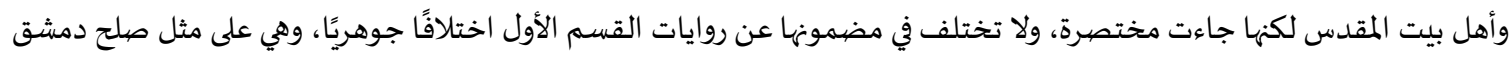
والمدن الشامية الكبرى. ويذكر في هذه الفئة كلًا من اليعقوي، وسعيد بن البطريق، والفئة الثانية: وروايات هذه الفئة طويلة، وذات

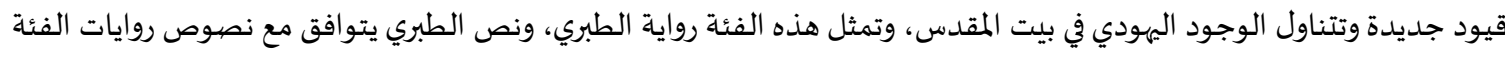

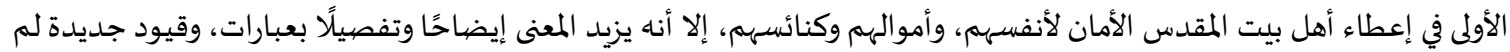

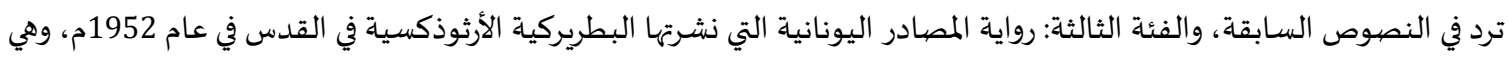

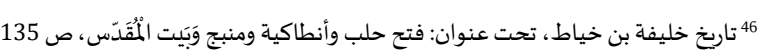

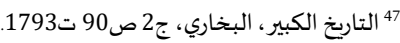

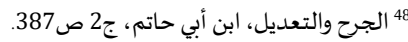

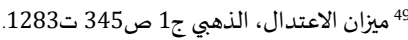

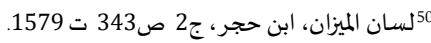

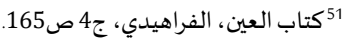


مؤرخة في العشرين من شهر ربيع الأول عام 15ه، تعد هذه الوثيقة من أبرز النصوص التي تناولها التغيير والزيادة، وهي على طولهيا

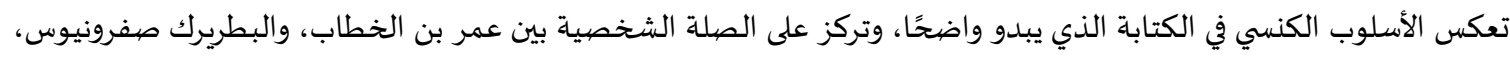

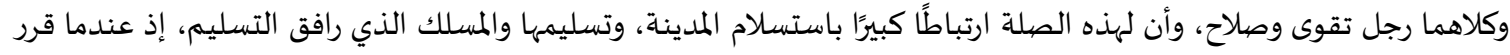

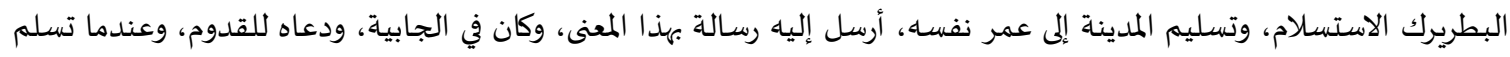

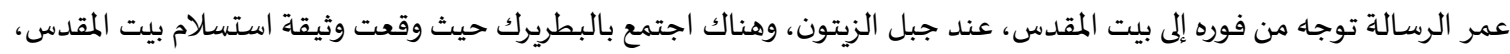
وتقدم عمر بعدها لدخول المدينة.

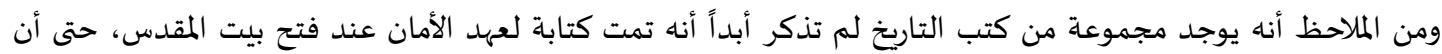

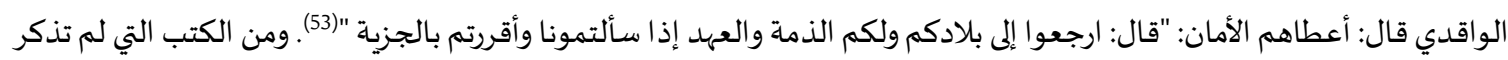

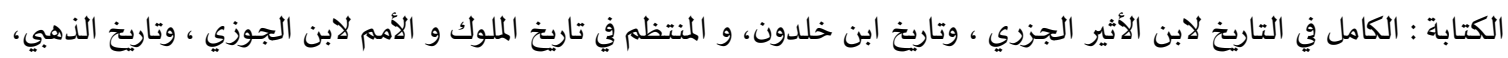

وتاريخ الخلفاء للسيوطي وغيرهم.

المطلب الأول: تحليل نص خليفة بن خياط (ت 240هـ):

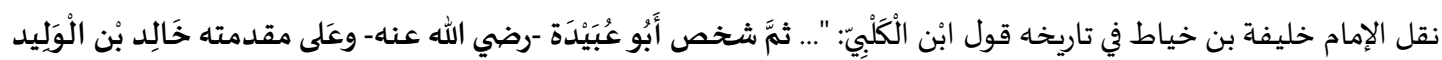

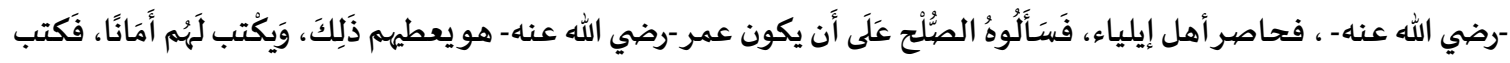

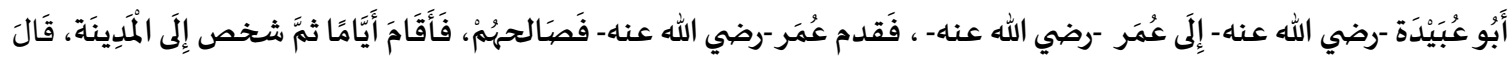

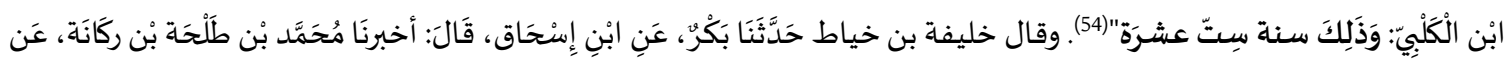

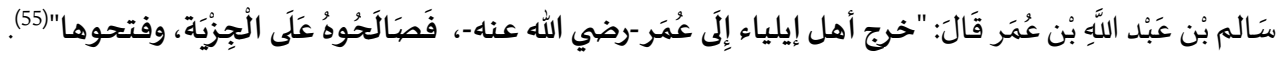

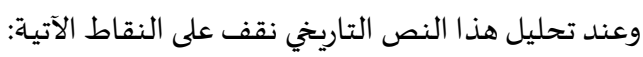

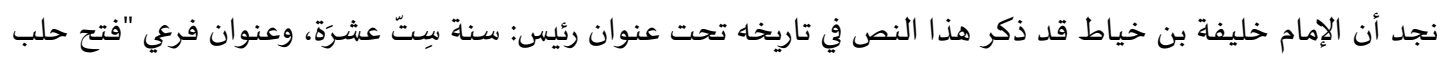
وأنطاكية ومنبج وَبَيت الْمُقَّدس". هذا النص تحديد أن أهل إيلياء طلبوا أن يكتب لهم أمير المؤمنين عمر -رضي الله عنه- كتاباً فيه أمان لهم، ولم يذكر فيه شيء من تفاصيل كتاب عهد الأمان الذي كتب.

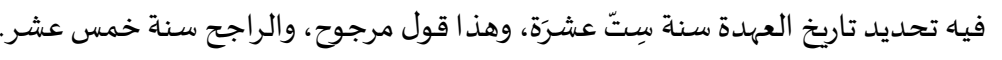

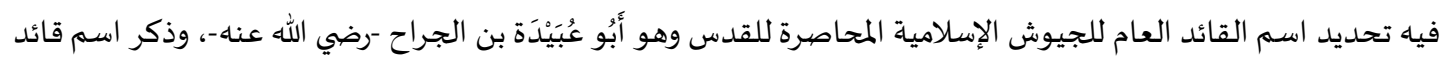

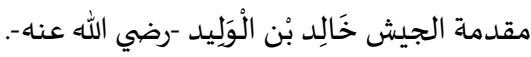

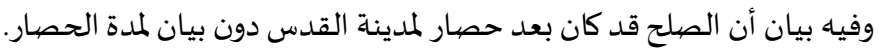

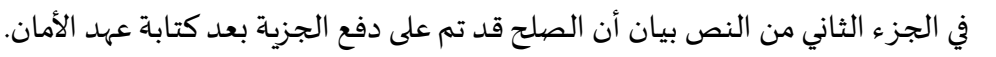

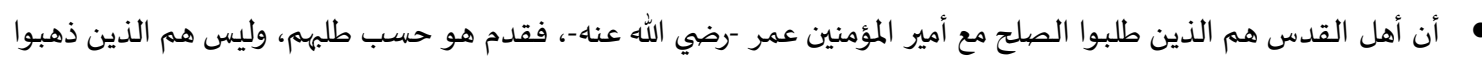

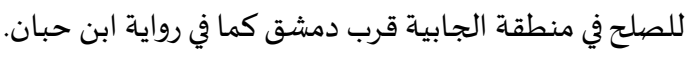

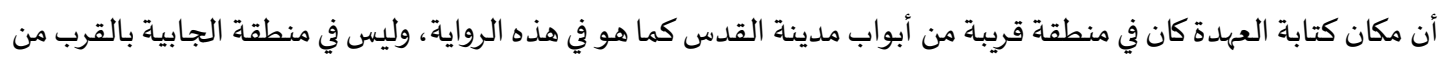
دمشق كما في رواية ابن حبان.

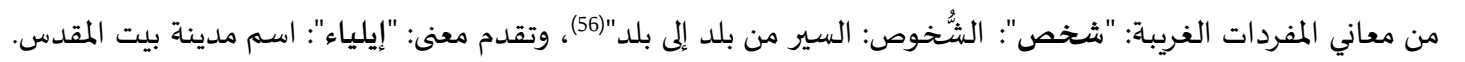

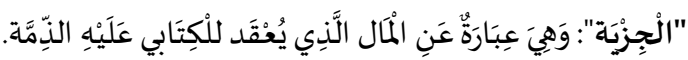

المطلب الثاني: تحليل نص اليعقوبي (ت284هـ):

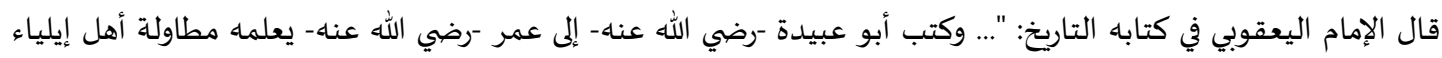

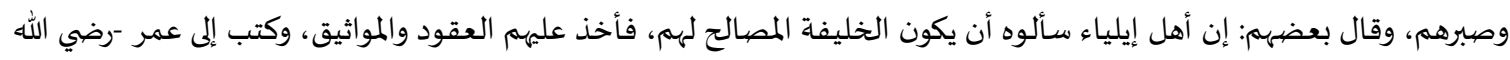

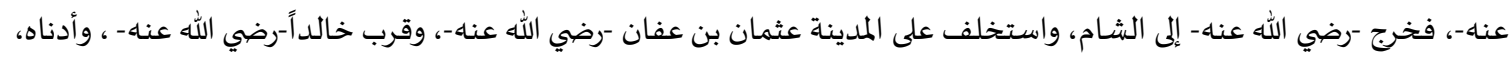

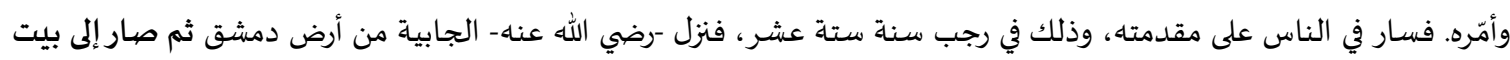




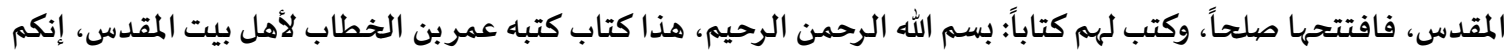

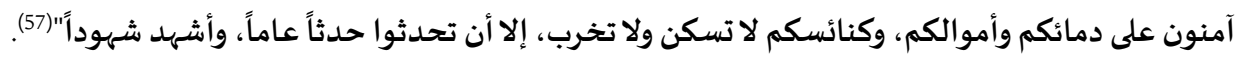
وعند تحليل هذا النص التاريخي نقف على النقاط الآتية: نجد أن الإمام اليعقوبي قد ذكر هذا النص في كتابه "التاريخ" تحت عنوان: "أيام عمر بن الخطاب"، بدون ذكر أي مصدر أو إسناد.

وهذا النص يثبت وجود كتاب مع ذكر جزء منه، حيث يوضح بعض الشيء عن تفاصيل مضيمونه. وفي وصف هذا النص من المفيد نقل رأي الباحث د.جاسر شفيق: أن اليعقوبي أورد نصاً مختصراً لهذا العهد (58). وقال الباحث محمد شراب: "عند دراسة هذا النص نجد أنه نص مجزوء من نص العهدة العمرية، فلا أتفق في هذا الموطن بالذات مع الطاعنين في هذا النص من جهة أن اليعقوبي ليس بثقة ويكذب كثيراً، فقد ذكر النص أنه أعطاهم الأمان على ألى

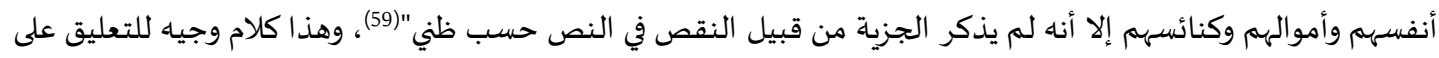
مجرد نقص النص! لأنها ليس فياء مخالفة لغيره. ويقول الباحث محمد شراب: "لذا لا أتفق مع د. موسى البسيط(60) في نقضها لهذا النص على اعتبار أن نص الطبري هو الأوثق سنداً"(61)، وهذا كلام صحيح لأنه لا داعي للنقض ما دامل دام يمكن الجمع بين النصين.

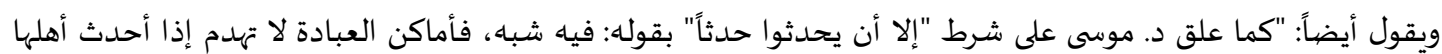

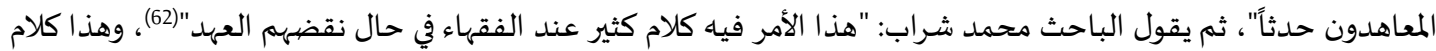
يحتاج إلى وقفة لأنه اعتبر النص الأكمل نص الطبري فهذه زيادة على النص الأكل تحتاج إلى تحقيق وتدقيق. ويقول أيضاً: " ثم علق على عدم ذكر أمير المؤمنين عمر بلقبه في النص نابع من كونه لا يقر للخليفة الراشد عمر بن الخطاب

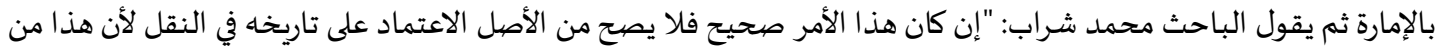

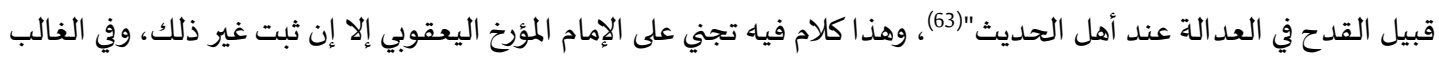
يكون ترك الألقاب من باب الاختصار فقط. وفي ختام كلام الباحث محمد شراب: رجح أن هذا النص جزء من نص الطبري ولا يتعارض معه تعارضاً واضحاً (64)، وهذه نتيجة

2. أن أهل القدس هم الذين طلبوا الصلح مع أمير المؤمنين عمر -رضي الله عنهاه.

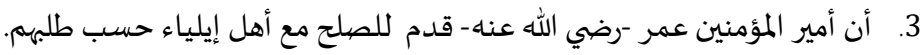
4. ت تحديد تاريخ العهدة سنة سِتِّ عشرَة. 5. تحديد اسم القائد العام للجيوش الإسلامية المحاصرة واسم قائد مقدمة الجيش.

• وقد انفرد اليعقوبي عن خليفة بن خياط بذكر شرطاً "إلا أن تحدثوا حدثاً عاماً".

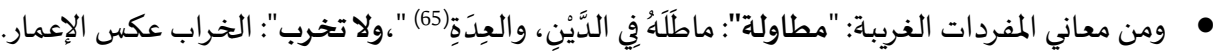

المطلب الثالث: تحليل نص الطبري (ت310هـ):

قال الإمام الطبري في كتابه التاريخ والمسسى بـ "تاريخ الرسل والملوك": "وعن خالد (66) وعبادة(67)، قالا: صالح عمر -رضي الله عنهـأهل إيلياء بالجابية، وكتب لهم فيها الصهلح لكل كورة كتاباً واحداً، ما خلا أهل إيلياء، بسم اللَّه الرحمن الرحيم هذا ما ما أعطى عبد والد

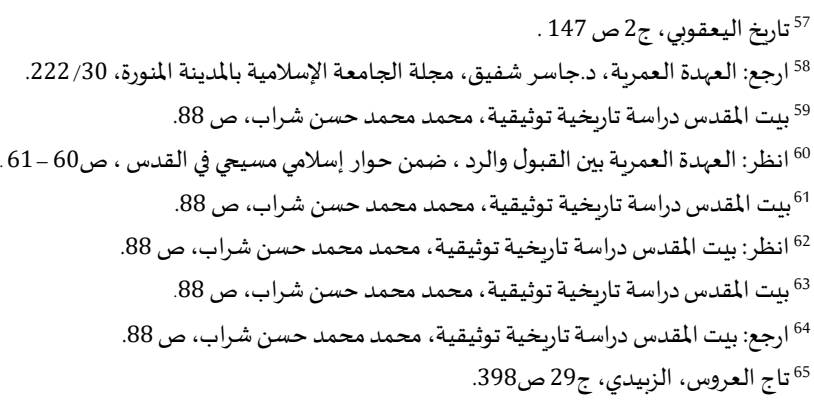


اللَّه عمر أمير المؤمنين أهل إيلياء من الأمان، أعطاهم أمانا لأنفسهم وأموالهم، ولكنائسهم وصلبانهم، وسقيمها وبريئها وسائر

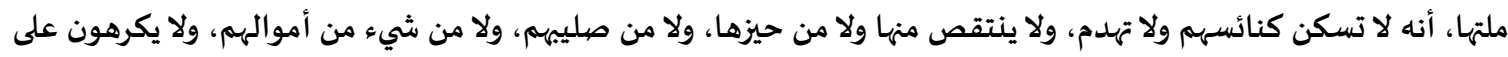

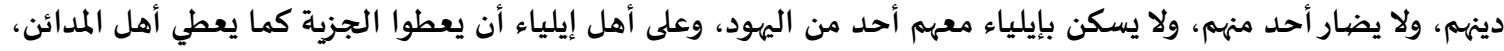

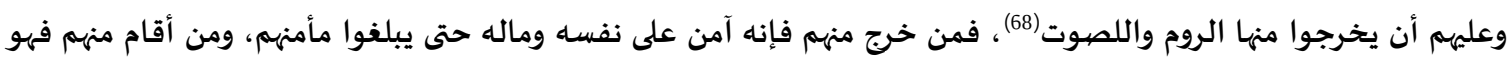

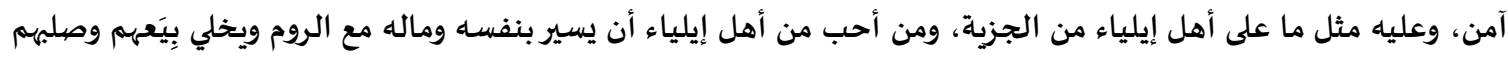

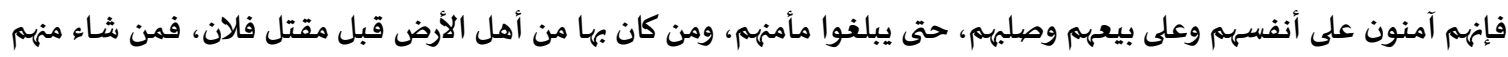

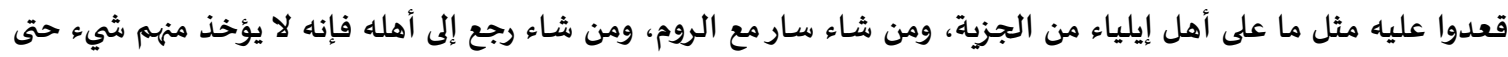

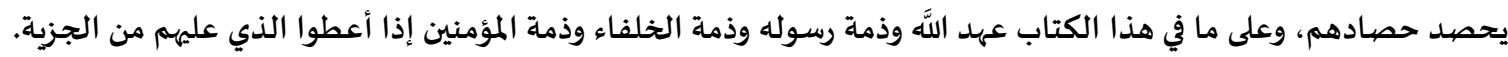

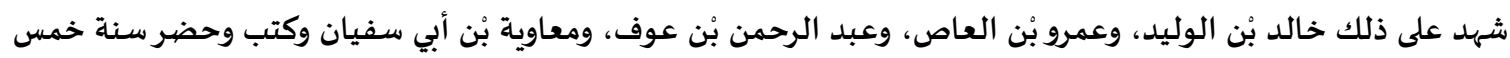
عشرة" (69).

وعند تحليل هذا النص التاريخي نقف على النقاط الآتية:

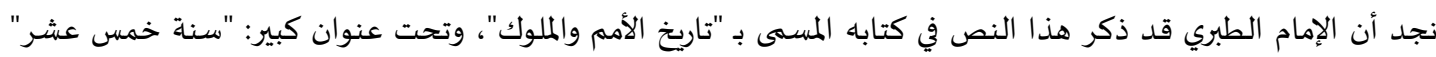
وعنوان فرعي: "ذكر فتح بيت المقدس". • • وهذا النص يكاد يكون الوحيد بين كتب التاريخ الذي يعطي نصاً متكاملاً، ويثبت وجود كتاب مع تفاصيل مضمونه.

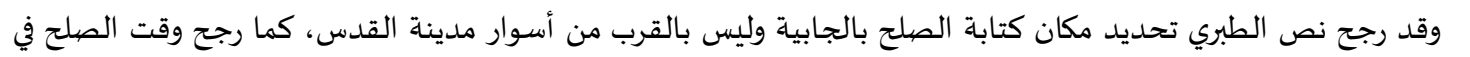
السنة الخامسة عشرة وليس السادسة عشرة.

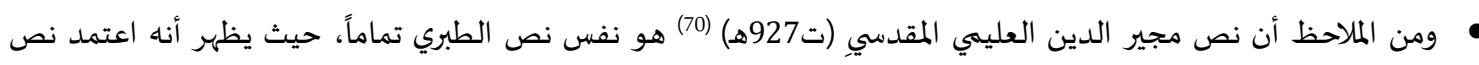

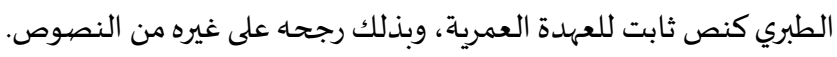

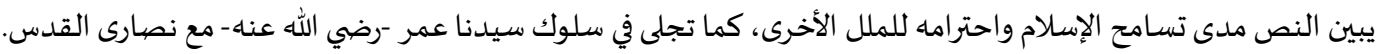

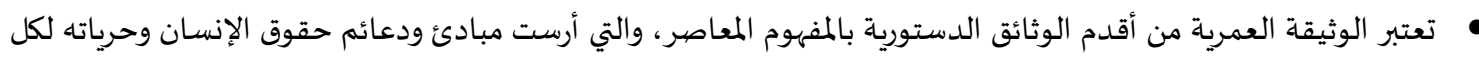

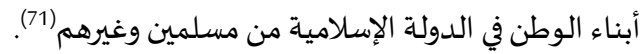
ويستنتج من المعاهدة ما يدعو إليه الإسلام من تسامح وتعايش وتضامن ومساواة باعتبارها قيم أخلاقية راقية الماهية لمعاملة الآخر ، ومن هذه القيم والحقوق: 1. حق كل إنسان في العيش بكرامة، دون الاعتداء عليه، بصرف النظر عن دينه أو جنسه. 2. يجب الحفاظ على أسرى الحرب، و تأمينهم. 3. عدم تدمير البيوت وأماكن العبادة.

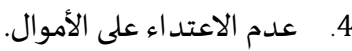
5. حق كل إنسان في الإقامة أينما اراد ولا يجبر على الإقامة في مكان معان معين أو الرحيل منه.

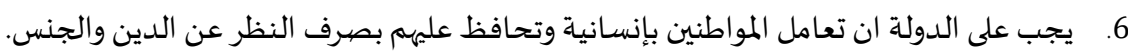
7. 8. الوفاء بالعهود والمواثيق. 9. اللجوء إلى السلم وعدم القتال ما أمكن ذلك. 10. حق الدولة في جمع الضرائب مقابل المحافظة على حياة المواطنين.

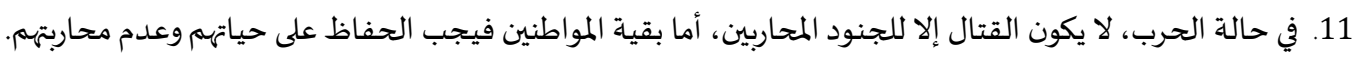

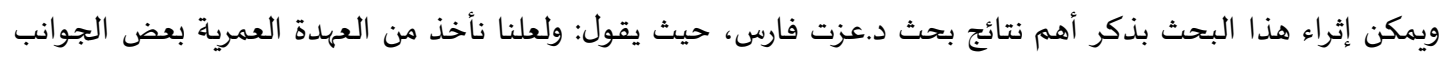

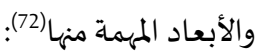

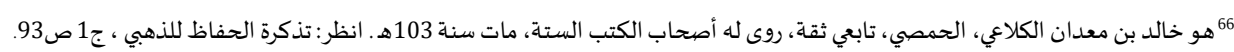

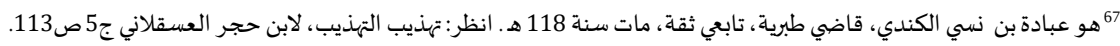
68 وهي اللصوص في لغة قبيلة طيء.

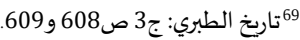

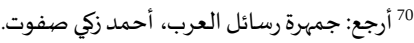
أر أرجع: حقوق الإنسان في وثيقة عمر بن الخطاب لأهل إيلياء، أطروحة ماجستير ، جامعة نايف العربية للعلوم الأمنية، كلية العدالة الجنائية، قسم الشريعة والقانون، 2015. 
1. أن العهدة العمرية بدأت بذكر اسم الله سبحانه وتعالى دليلا على الإيمان باه، ولأن كل ما لم يذكر اسم الله عليه فهو أبتر، أضف الى ذلك أن اسم الله يعني الأمان والاطمئنان وذلك على عادة الرسائل في في صلدر الإسلام. وفهيها اظهار التواضع لله سبحانه حيث قالت المعاهدة: هذا ما أعطى عبدالله عمر بن الخطاب آ، أي: أنه يقر بالعبودية لله الله

3. وإن لفظة أعطى تومئ الى أن هذه الميزات التي قدمتها المعاهدة هي هبة ومنحة من أمير المؤمنين ح لأهل ايلياء، وليست حقا من حقوقهم.

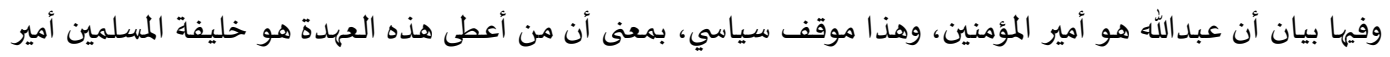

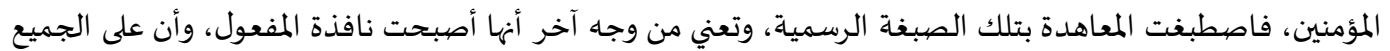
أن يطبقوا بنودها بدقة وأمانة. 5. وتميزت الألفاظ بالقوة والوضوح لأن الفاروق ح كان حريصاً على الإفهام وتوضيح المطلوب، مع إكساب العهدة جواً من القوة لإتمام العمل بها لأهميتها ولزوم الأمر في تأديتها.

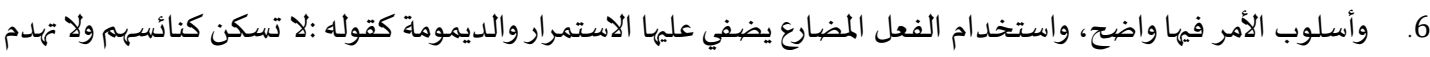
ولا ينتقص منها، ولا يكرهون على دينهم، ولا يسكن بإيلياء معهم، لا يؤخذ منهم..، وعليهم أن يعطوا الجزية، وعلهيهم أن الن النهان

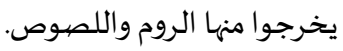

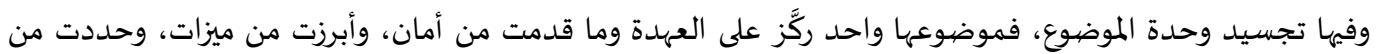

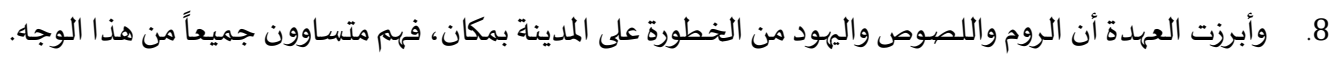

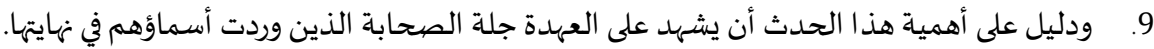

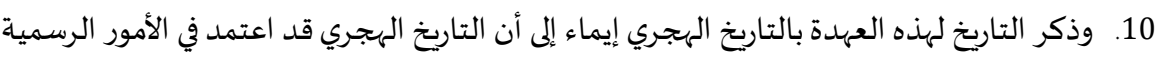

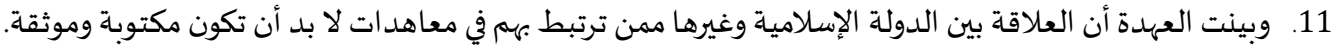

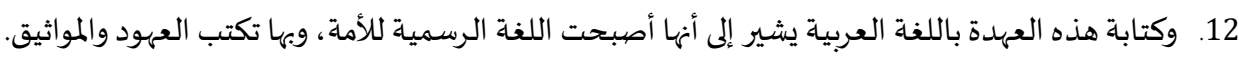

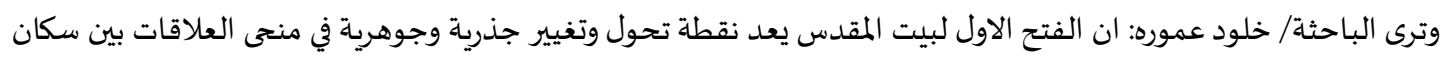

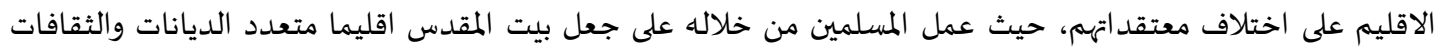

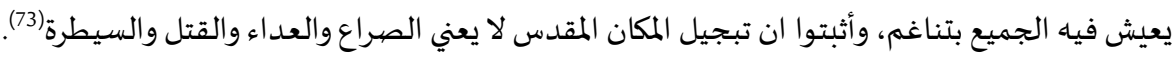

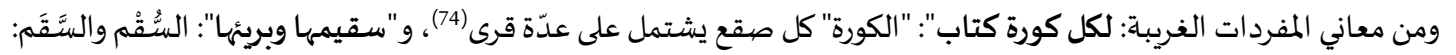

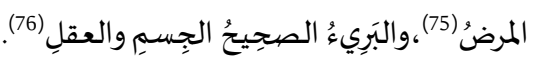

المطلب الر ابع: تحليل نص المطهربن طاهر (ت355 هـ):

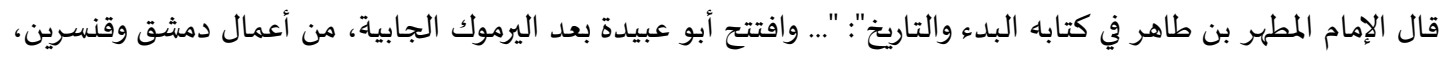

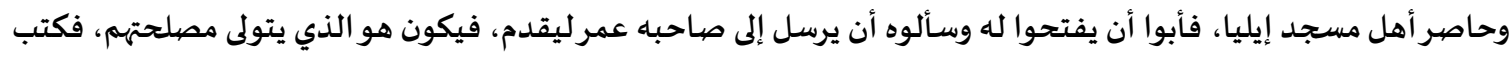

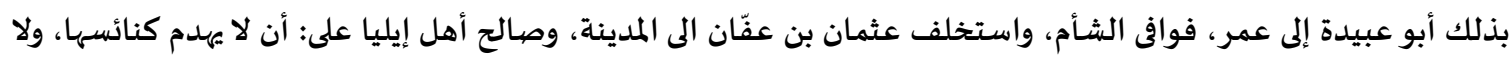

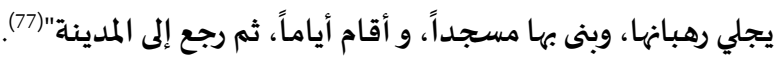
وعند تحليل هذا النص التاريخي نقف على النقاط الآتية:

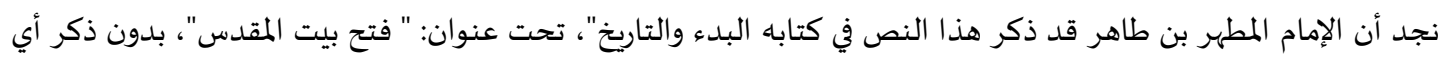

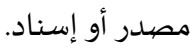
وهذا النص يثبت وجود كتاب مع ذكر جزء منه، حيث يوضح بعض الشيء عن تفاصيل مضمونه. هونلاحظ اتفاق هذا النص عند المطهر بن طاهر مع نصي اليعقوبي خليفة بن خياط دون نص الطبري في:

372 ق قراءة في العهدة العمرية، د.عزت محمود فارس، ص219.

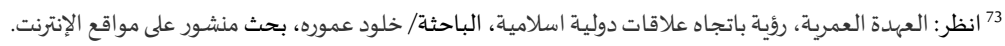

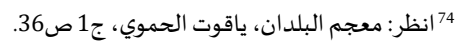

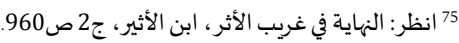

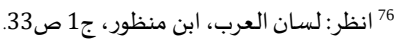

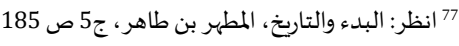




$$
\begin{aligned}
& \text { 1. - أن أصلح كان بعد حصار. } \\
& \text { 2. أن أهل القدس هم الذين طلبوا الصلح مع أمير المؤمنين عمر -رضي الله عنه -. }
\end{aligned}
$$

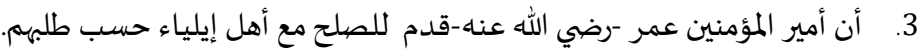

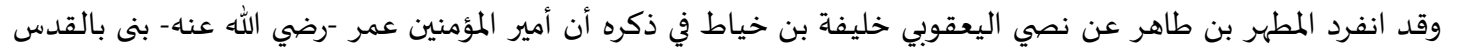

$$
\text { مسجداً"، دون نص الطبري أيضاً. }
$$

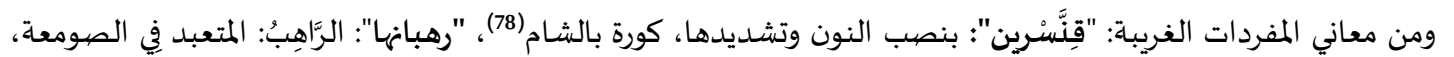

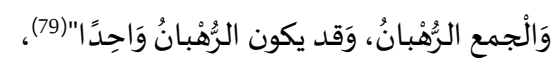

$$
\text { المطلب الخامس: تحليل نص الأزدي (ت443 هـ): }
$$

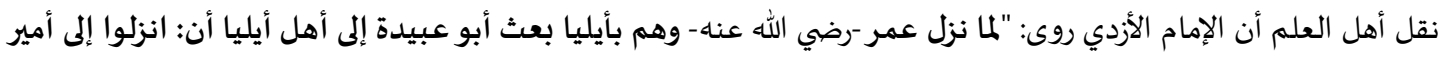
المؤمنين، فاستوثقوا لأنفسكم، فنزل إليه ابن الجعد(80)، في ناس من عظمائهم، فكتب لهم الإدمئ عمر -رضي الله عنه- كتاب الأمان والصلح" (81).

وعند تحليل هذا النص التاربخي نقف على النقاط الآتية:

لم يجد الباحث هذا النص مطبوعاً إلا عند صاحب كتاب "مجموعة الوثائق السياسية للعهد النبوي والخلافة الراشدة" وقد

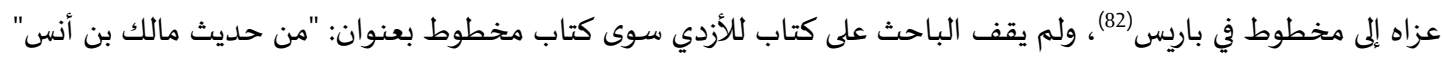

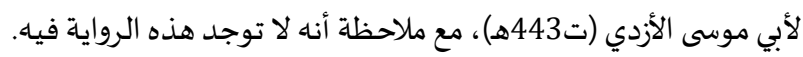

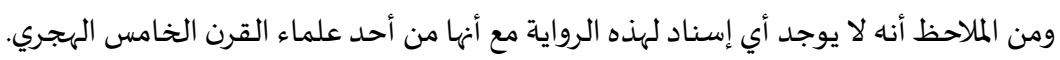
وهذا النص يثبت وجود كتاب أمان دون بيان أي تفاصيل عن مضهمونه. • ونلاحظ اتفاق هذا النص مع النصوص الثلاثة السابقة عند الأمة: خليفة بن خياط واليعقوبي والمطهر بن طاهر، دون نص الطبري في:

1. أن الصلح كان بعد حصار ، ونلمس ذلك من قول أبو عبيدة -رضي الله عنه -: "انزلوا إلى أمير المؤمنين".

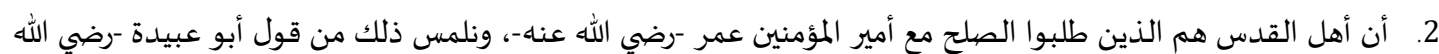

عنه-: "فاستوثقوا لأنفسكم". 3. أن أمير المؤمنين عمر -رضي الله عنه- قدم للصيلح مع أهل إيلياء حسب طلهيه، -رضي الله عنه-، ويمكن أن نلمس ذلك من قول الإمام الأزدي: "لما نزل عمر -رضي الله عنده- وهم بأيليا". • وقد انفرد الأزدي عن النصوص الأربعة السـابقة بذكر اسم زعيم النصارى الذي كتب لله عمر -رضي الله عنه- كتاب الأمان والذي أجرى معه الصلح وهو "ابن الجعد" أو ابن الجعيد". مع ملاحظة أنه ذكر الصلح ولم يذكر الجزية، وهذا يكون من باب النقص في الرواية كما أشرنا سابقاً. • ومن الملاحظ أيضاُ أن ضبط اسم المدينة "بأيليا" و"أهل أيليا" بالهمزة المفتوحة بدلاً من الهمزة المكسور في الروايات السابقة.

المطلب السـادس: تحليل نص ابن كثير (ت كات

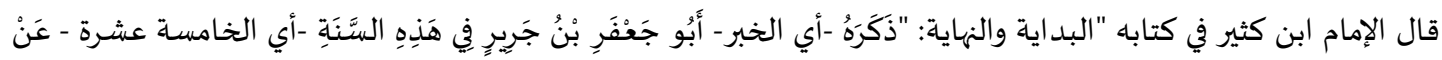

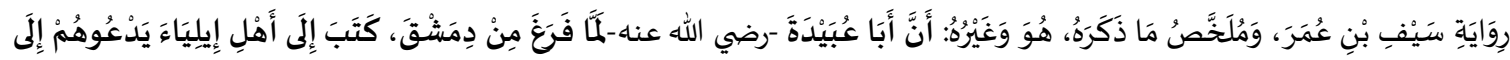

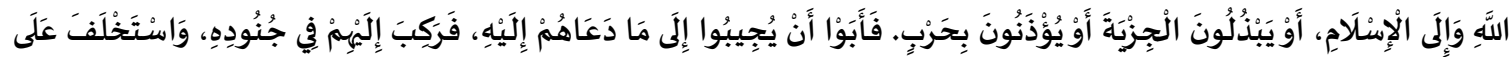

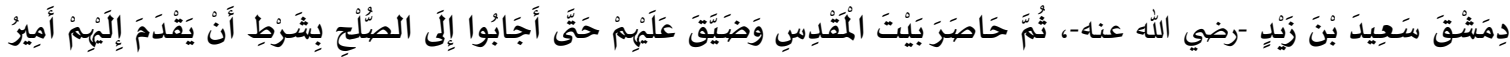

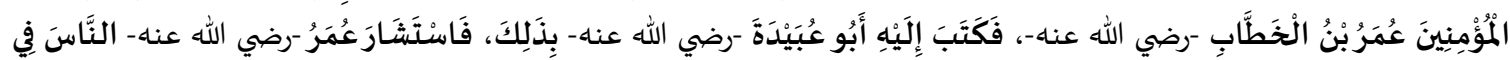

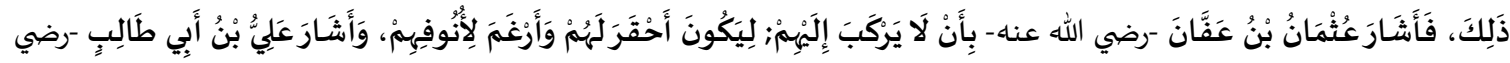

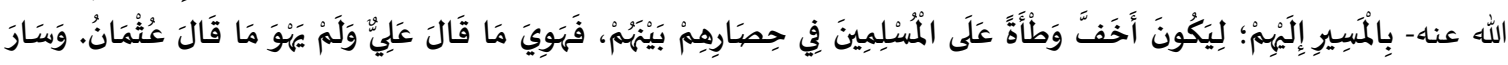

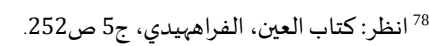

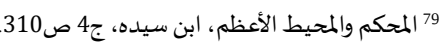
80 ابن الجعد أو ابن الجعيد.

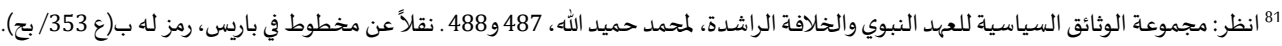

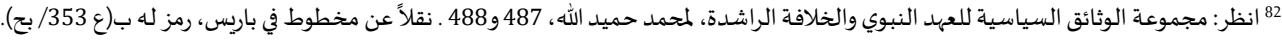




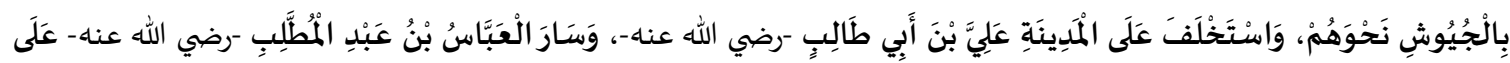

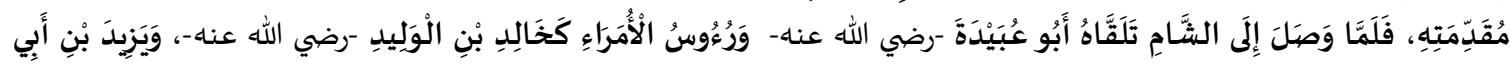

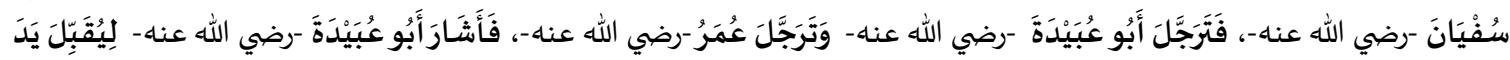

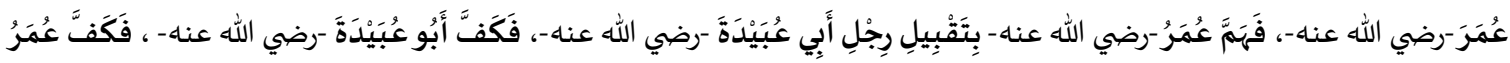

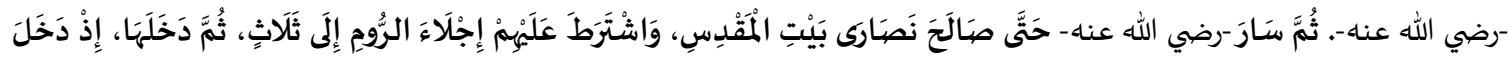

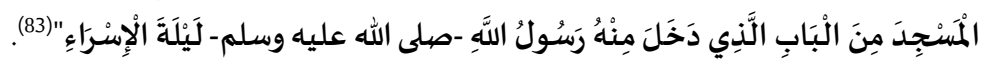
وعند تحليل هذا النص التاريخي نقف على النى النقاط الآتية:

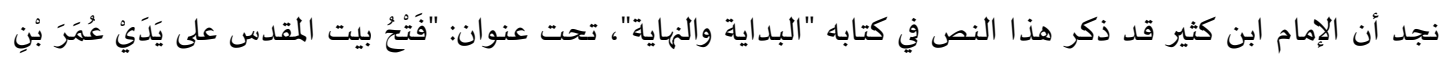

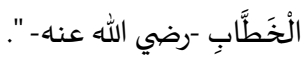
وهذا النص بدون إسناد متصل، إلا أحد أشهر رواته وهو أبو جعفر جرير من رواية سيف بن عمر، وهذا لا يكفي والإمام ابن كثير من علماء القرن الثامن الهجري.

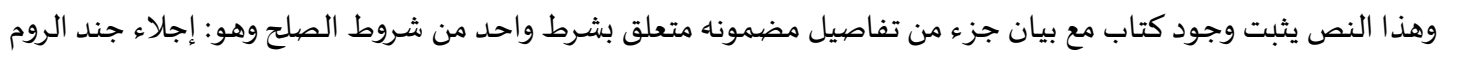
من مدينة القدس خلال ثلاثة أيام. ونلاحظ اتفاق هذا النص مع النصوص الأربعة السابقة عند الأمة: خليفة بن خياط واليعقوبي والمطهر بن طاهر والأزدي، دون

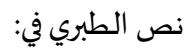

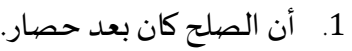

$$
\begin{aligned}
& \text { 2. } \\
& \text { 3. أن أمير المؤمنين عمر -رضي الله عنه- قدم للصيلح مع أهل إيلياء حسب طلبهم. } \\
& \text { وقد انفرد نص ابن كثير عن النصوص الخمسة السابقة في: }
\end{aligned}
$$

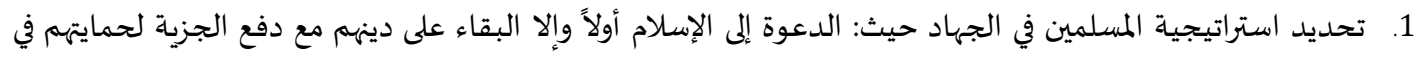

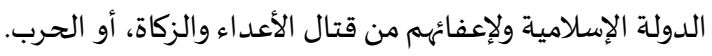

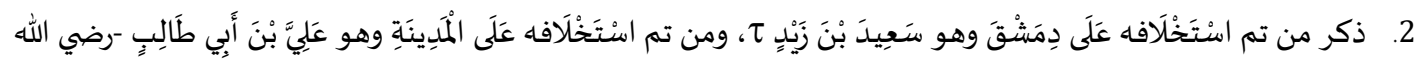

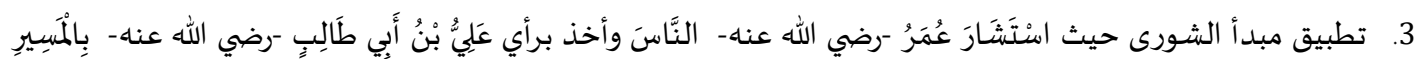

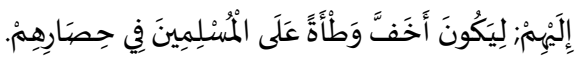

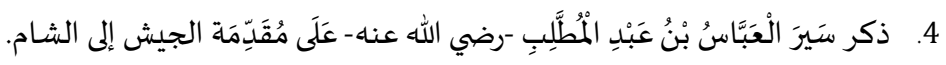

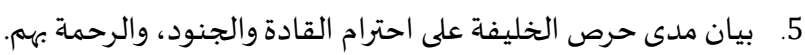

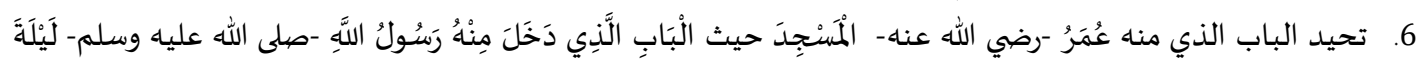

$$
\text { الْإِنَرَاء. }
$$

وقد رجح نص ابن كثير تحديد وقت الصلح في السنة الخامسة عشرة.

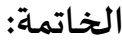

الحمد لله رب العالمين حمداً "لا أحصي ثناءً عليك، أنت كما أثنيت على نفسك" (84)، كما وأصلي وأسلم على نبيك "اللهم صلّ على إلى محمد وعلى آل محمدٍ، كما صليت على آل إبراهيم، إنك حميد مجيد لهيد" (85). أما بعد: لقد مّن الله تعالى علّي بإتمام هذا البحث فإن أحسنت فمن الله وحده، وإن كان غير ذلك فمن نفسي ومن الشيطان، وحسبي أني 
ولقد تناول هذا البحث تحليل نَصّ العهدة العمرية عند المُحَدَّثين والمؤرخين فيما اصطلح العلماء على تسميته بالعهدة العمرية

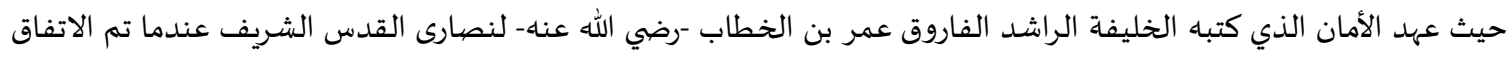
على فتحها صلحاً، مع المقارنة بين جهود كل من أهل الحديث والمؤرخين في الاهتمام بنص العهدة وتحليلها. أولاً: النتائج:

وقد توصل البحث إلى عدة نتائج كان أهمها ما يلي: تبين أن اهتمام المؤرخين بنص العهدة العمرية وتحليله كان أكثر من المحدثثين. ومن المهم بيان أن من نتائج العهدة العمرية الخالدة هو بقاء علاقة مميزة بين مكونات الشعب الفلسطيني في محاربة المحتل المهابل

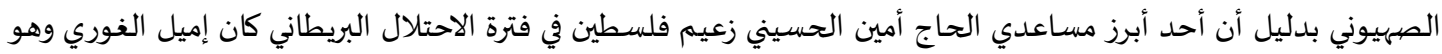

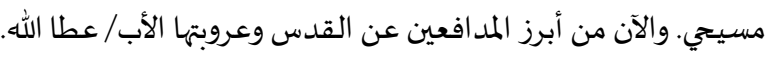

أن العهدة العمرية تختلف عن الشروط العمرية، وهذا البحث مخصص لتحرئ لتحليل نصوص العهدة دون ما يعرف بالشروط العمرية. أن أكثر نص اهتم باه المؤرخون في التحليل كان نص الإمام الطبري. أن الإمام ابن عساكر في كتابه نصوص لها أسـانيد على طريقة المحدثين يمكن دراستها والحكم عليها، ونصوص أخدون أخرى ليس لها أسانيد وتعتمد على سرد الحدث على طريقة المؤرخين. تمثل العهدة العمرية أروع صور التسامح الديني بشهادة بعض المستشرقين مثل: المؤرخ "جوستاف لوبون" في كتابه "حضارة

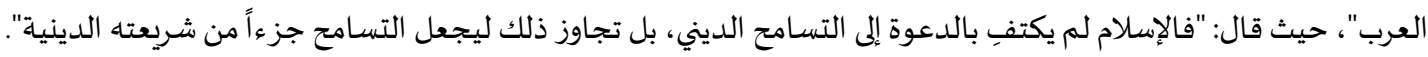
من نتائج تحليل نصوص هذه هي العهدة العمرية: أن فيها سماحة الإسلام، وحفظ الحقوق، ومراعاة واحترام لشرائع الآخرين، ومحافظة على العهود والمواثيق، وعدم الإكراه في الدين.

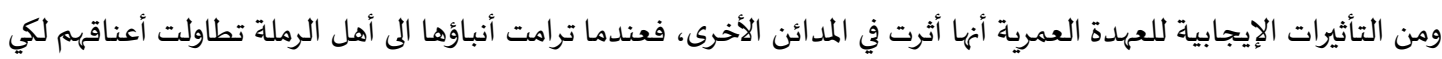
يعقدوا مع أمير المؤمتين عمر بن الخطاب معاهدة مثلها، ثم فعل مثلهم أهل اللد.

يتفق الباحث على نتائج د.شفيق في بحثه: أن هذه الروايات لنصوص العهود المسماة بالعهدة العمرية قد وسعت وطورت على الزمن تبعاً لتطور أحوال أهل، وأقرب ما تكون للحقيقة، هي نصيوص: اليعقوبي، وابن البطريق وابن الجوزي، وأن ما ورد ورد في نصي

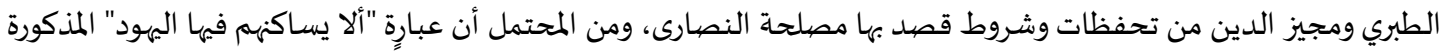

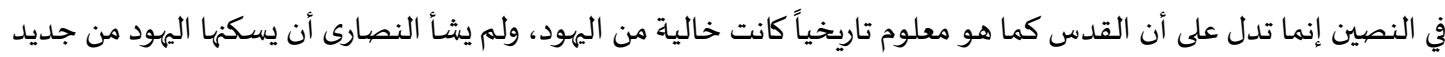
تحت حكم المسلمين. (86)

$$
\text { ثانياً: التوصيات: }
$$

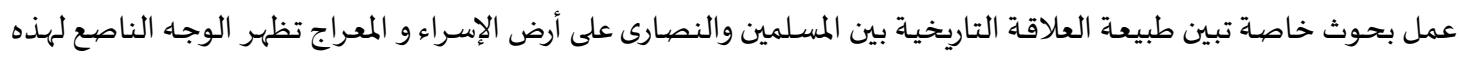
العلاقة من الفتح العمري وحتى العصر الحاضر. إجراء دراسـات أخرى مقارنة بين المُحَدّثين والمؤرخين في تحليل نصوص وثائق أخرى مهمة مثل: صلح الحديبية، وصحيفة المقاطعة (... - وغيرهما. إجراء بحث خاص بتحليل نصوص ما يعرف بالشروط العمرية عند الفقهاء. 
1. إبراهيم، محمود (1985). كتاب فضيائل بيت المقلس في مخطوطات عربية قديمة. ط. منشورات معهد المخطوطات العربية. المنظمة العربية للتربية والثقافة والعلوم. الكويت.

2. ابن الأثير الجزري، محمد بن محمد بن عبد الكريم الشيباني (1987). الكامل في التاريخ. للإمام. ط. دار الكتب العلمية. بيروت، لبنان.

3. ابن الأثير الجزري، محمد بن محمد بن عبد الكريم الشيباني (1988). النهاية في غريب الحلديث والأثر. ط. دار إحياء الكتب

العربية. مصر.

4. الإمام أحمد، أحمد بن محمد بن حنبل الشيباني (2001 و1995). مسند الإمام أحمد بن حنبل. ط. مؤسسة الرسالة. و ط. دار

الحديث. القاهرة.

5. البخاري، محمد بن إسماعيل (1987). صحيح البخاري. ط. دار ابن كثير.

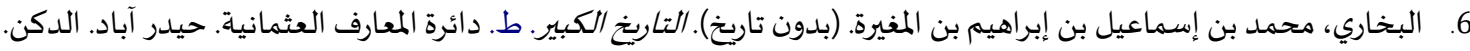

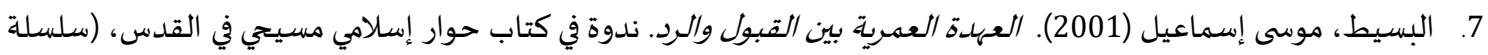
لقاءات وحوارات): الجمعية الفلسطينية الأكاديمية للشؤون الدولية. القدس.

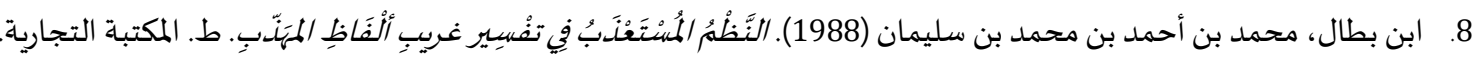
مكة المكرمة.

9 9. البيهي، أحمد بن الحسين بن علي (2003). السنن الكبرى. ط. دار الكتب العلمياة: بيروت. لبنان. 10. ابن أبي حاتم، عبد الرحمن بن محمد بن إدريس بن المنذر (1952). الجبح والتعديل. ط. دار إحياء التراث العربي. بيروت.

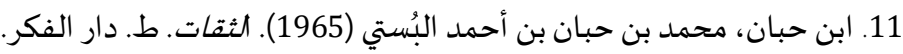

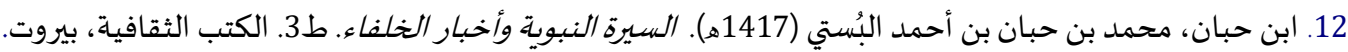

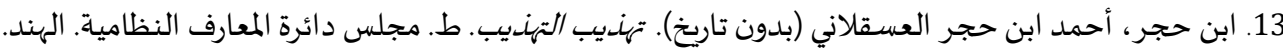

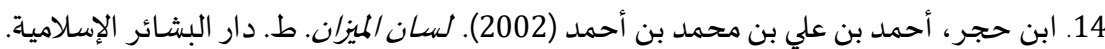

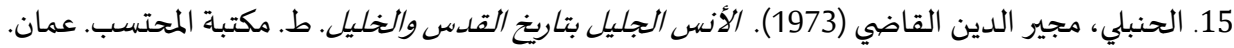
16. حميد الله، محمد (1987). مجموعة الوثائق السياسية للعهد النبوي والخلافة الراشدة. داشئ دار النفائس. بيروت. 17. الخالدي، وليد (2000). القلدسيد من العهدة العمبية إلى كامب ديفل الثانية. ط. مؤسسة الدراسات الفلسطينية. بيروت، لبنان.

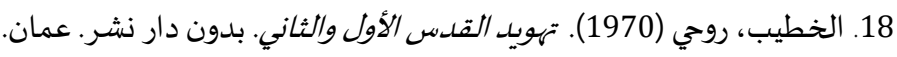
19. ابن خلدون، عبد الرحمن بن محمد بن محمد (2000). تاريخ /بن خلدون، المسسى ديوان المبتدأ والخبر في تاريخ العبرب والبربر

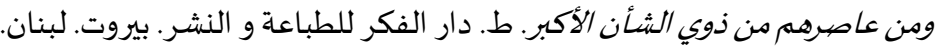
20. ابن خياط، خليفة العصفري (1397هـ). تاريخ خليفة بن خياط. ط2. دارئ دار القلم. دمشق ـ ومؤسسة الرسالة. بيروت.

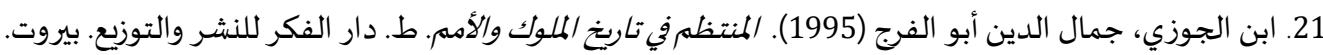
22. الدباغ، مصطفى مراد (1975). بلادنا فلسطين. ط. دار السورئ الطليعة. بيروت. 23. الذهبي، شمس الدين محمد بن أحمد بن عثمان (1987). تاريخ الإسلام ووفيات المشاهير والأعلام، ط. دار الكتاب العربي. بيروت.

24. الذهبي، شمس الدين محمد بن أحمد بن عثمان (بدون تاريخ). تذكرة الحفاظ. ط. دار الفكر العربي.

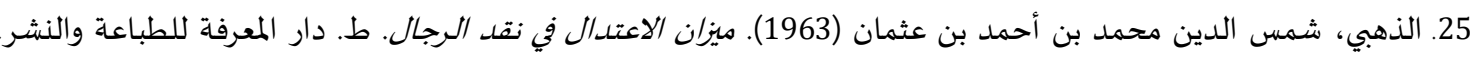
بيروت، لبنان.

26. الرازي، محمد بن أبي بكر (1995). مختار الصحاح. لط. لـ مكتبة لبنان ناشرون. بيروت.

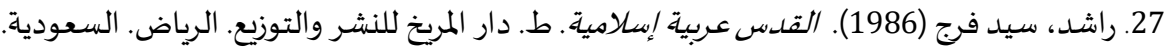
28. الراغب الأصفهاني، الحسين بن محمد (1412ه). المفردات في غريب القرآن. ط. دار القلم. الدار الشامية. دمشق. وبيروت. 29. ابن رجب، زين الدين عبد الرحمن بن أحمد بن الحسن (1996). فتح الباري شرح صحيح البخاري. ط. مكتبة الغرباء الأثرية. المدينة النبوياة. 30. الزيان، رمضيان إسحاق (2006). روايات العهدة العمرية - دراسة توثيقية. مجلة الجامعة الإسلامية بغزة: (سلسلة الدراسات الإسلامية): 14(2): 203-169. 
31. السيوطي، جلال الدين (1994). تاريخ الخلفاء. ط2. دار الجيل. بيروت.

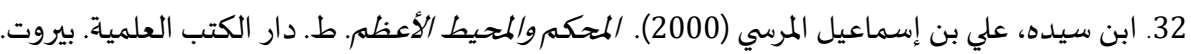

33. الصنعاني، عبد الرزاق بن همام (1972). مصنف عبد الرزاق الصنعاني. ط. المكتب الإسلامي. بيروت.

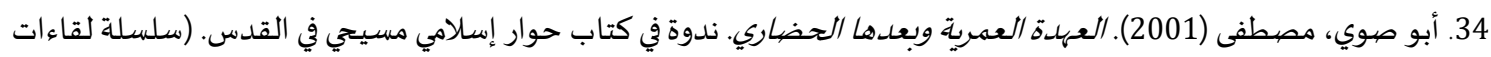

وحوارات): الجمعية الفلسطينية الأكاديمية للشؤون الدولية. القدس.

35. ابن طاهر، المطهر (بدون تاريخ). البلدء والتاريخ. ط. مكتبة المثنى. بغداد. ومكتبة الثقافة الدينية. بور سعيد.

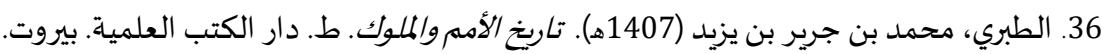

37. طقوش، محمد سهيل. (2003). تاريخ الخلفاء الراشدين الفتوحات والإنجازات السياسية. د. دار النفائس.

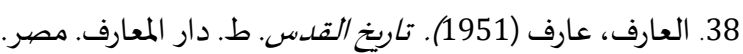

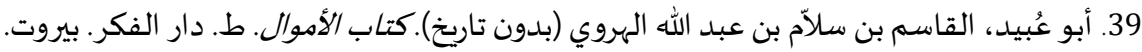

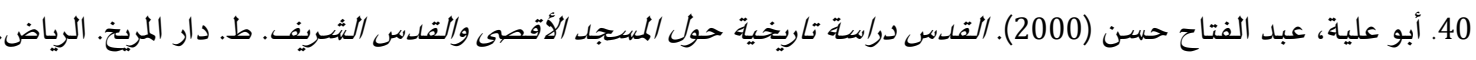
السعودياة.

41. ابن كثير، إسماعيل بن عمر القرشي (1997). البد/ية والنهاية. ط. دار هجر للطباعة والنشر والتوزيع والإعلان.

42. ابن كثير، إسماعيل بن عمر القرشي (بدون تاريخ). تفسير /بن كثير. ط. دار إحياء الكتب العربية، مصرير.

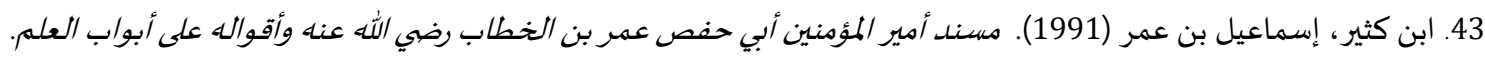
ط. دار الوفاء. المنصورة.

44. لحام، مارون (2001)." العهلة العمسية" . مقال في كتاب القدس. مركز اللقاء للدراسات الدينية والتراثية في الأرض المقدسة، 45. العابدي، محمود (1972). كتاب قلسنا. ط. معهد البحوث والدراسات العربية. المنظمة العربية للتربية والثقافة والعلوم. القاهرة.

46. ابن عساكر ، علي بن الحسن ابن هبة الله بن عبد الله (1995). تاريخ مدينة دمشق وذكر فضلها وتسمية من حلها من الأماثل. ط. دار الفكر. بيروت.

47. العسلي، كامل جميل (1983). وثائق مقدسية تاريخية. ط. مطبعة التوفيق. عمان.

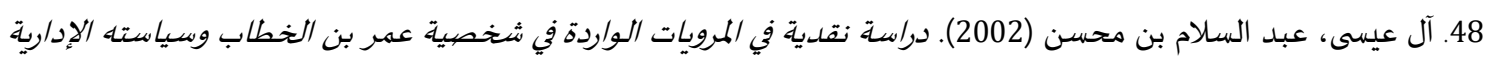
رضي الله عنه. ط. عمادة البحث العلمي بالجامعة الإسلامية. المدينة المنورة، المملكة العربية السعودياة.

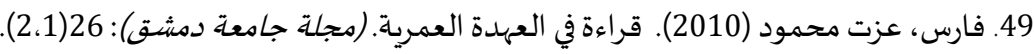

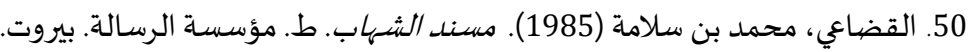

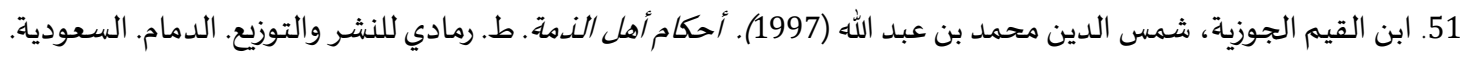

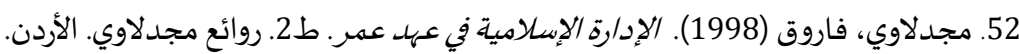

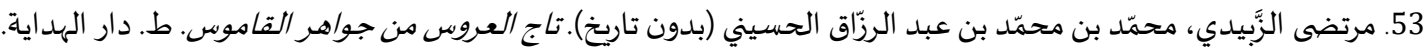

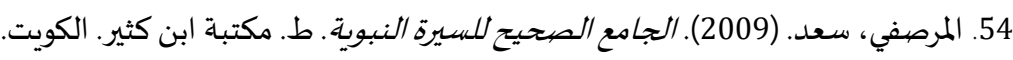
55. مسلم، مسلم بن الحجاج النيسابوري (1374هـ). صحيح مسلم. ط. ط. دار إحياء التراث العربي. بيروت.

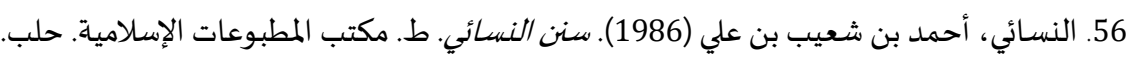

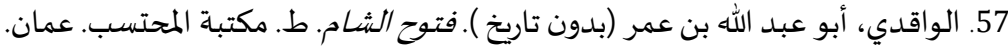

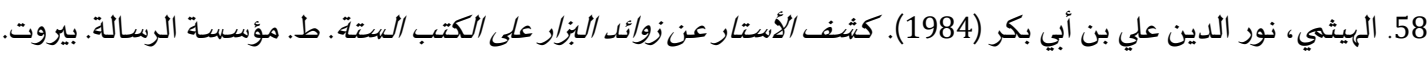

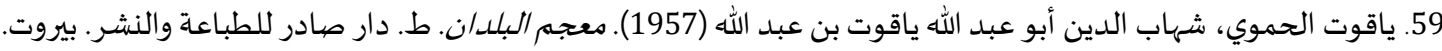
60. اليعقوبي، أحمد بن أبي يعقوب بن جعفر بن وهب (1980). تاريخ اليعقوبي. بدون دار نشر. 


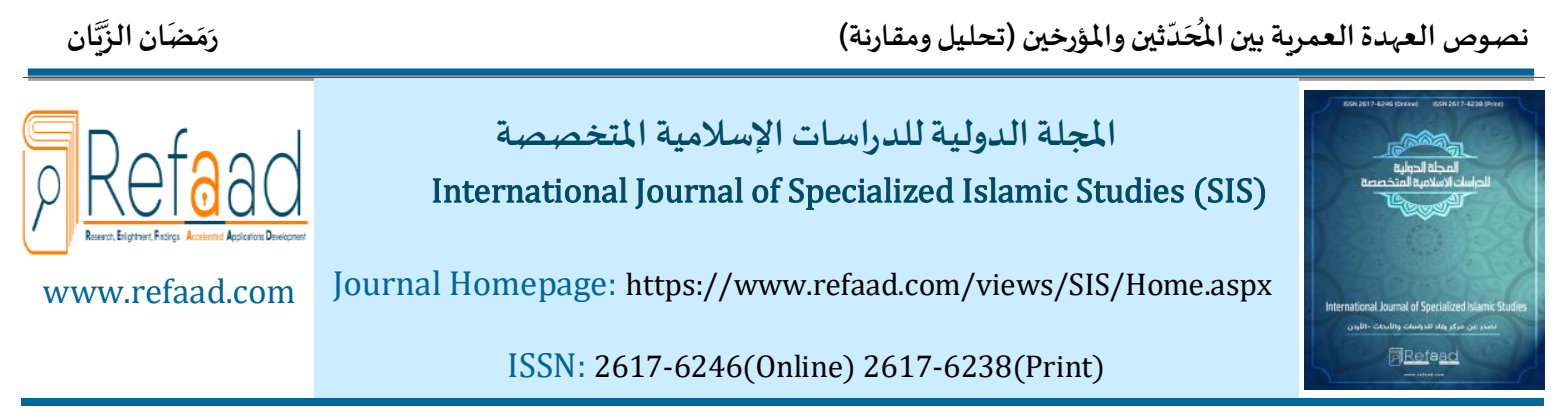

\title{
The texts of the Omeria treaty between the modernists and historians (Analysis and comparison)
}

\author{
Ramadan Isaac AL-Zayyan \\ Associate Professor of Hadith and its Sciences, Department of Islamic Studies, \\ Al-Aqsa University, Gaza \\ ri.alzayan@alaqsa.edu.ps
}

Received: 21/9/2021 Revised: 5/10/2021 Accepted: 23/10/2021 DOI: https://doi.org/10.31559/SIS2021.6.2.1

Abstract: This research deals with the analysis of the texts of the Omari Covenant of the modernists and historians and the comparison between their efforts. Among the most important findings of the research are the following: it was found that the historians' interest in the text of the Omari Covenant and its analysis was more than that of the modernists, it is not logical to account for the historical novels with the rules of modern criticism with accuracy, the text that historians were mostly interested in in the analysis was the text of Imam al-Tabari, and the testament represented Omari is the most wonderful shape of religious tolerance, according to the testimony of some orientalists. Among the results of analyzing the texts of the Omari Covenant are that: it represents the tolerance of Islam towards non-Muslims, it is the preservation of the rights of others, it is observant of the laws of others, it is respectful for their privacy, it is preservng covenants, and it is assertive in that there is no compulsion to enter the religion of Islam.Among the positive effects of the Omari Covenant is that it affected other cities, when its news reached the people of Ramla, their necks extended in order to make a similar treaty with the Prince of the Two Mothers, Omar Ibn AlKhattab, may God be pleased with him, and so did the people of Lod.

Keywords: The Omaria Covenant textual analysis; comparison; modernists; historians.

\section{References:}

1. Abn Alathyr Aljzry, Mhmd Bn Mhmd Bn 'bd Alkrym Alshybany (1987). Alkaml Fy Altarykh. Llemam. T. Dar Alktb Al'lmyh. Byrwt, Lbnan.

2. Abn Alathyr Aljzry, Mhmd Bn Mhmd Bn 'bd Alkrym Alshybany (1988). Alnhayh Fy Ghryb Alhdyth Walathr. T. Dar Ehya' Alktb Al'rbyh. Msr.

3. Albkhary, Mhmd Bn Esma'yl (1987). Shyh Albkhary. T. Dar Abn Kthyr.

4. Albkhary, Mhmd Bn Esma'yl Bn Ebrahym Bn Almghyrh. (Bdwn Tarykh). Altarykh Alkbyr. T. Da'rt Alm'arf Al'thmanyh. Hydr Abad. Aldkn.

5. Albsyt, Mwsa Esma'yl (2001). Al'hdh Al'mryh Byn Alqbwl Walrd. Ndwh Fy Ktab Hwar Eslamy Msyhy Fy Alqds, (Slslt Lqa'at Whwarat): Aljm'yh Alflstynyh Alakadymyh Llsh'wn Aldwlyh. Alqds.

6. Abn Btal, Mhmd Bn Ahmd Bn Mhmd Bn Slyman (1988). Alnźmu Almust'dbu Fy Tf́syr Ghryb.Alfaz.Almhádb. T. Almktbh Altjaryh. Mkh Almkrmh.

7. Albyhqy, Ahmd Bn Alhsyn Bn 'ly (2003). Alsnn Alkbra. T. Dar Alktb Al'lmyh: Byrwt. Lbnan.

8. Aldbagh, Mstfa Mrad (1975). Bladna Flstyn. T. Dar Altly'h. Byrwt.

9. Aldhby, Shms Aldyn Mhmd Bn Ahmd Bn 'thman (1987). Tarykh Aleslam Wwfyat Almshahyr Wala'lam, T. Dar Alktab Al'rby. Byrwt.

10. Aldhby, Shms Aldyn Mhmd Bn Ahmd Bn 'thman (Bdwn Tarykh). Tdkrh Alhfaz. T. Dar Alfkr Al'rby.

11. Aldhby, Shms Aldyn Mhmd Bn Ahmd Bn 'thman (1963). Myzan Ala'tdal Fy Nqd Alrjal. T. Dar Alm'rfh Lltba'h Walnshr. Byrwt, Lbnan. 
12. Ebrahym, Mhmwd (1985). Ktab Fda'l Byt Almqds Fy Mkhtwtat 'rbyh Qdymh. T. Mnshwrat M'hd Almkhtwtat Al'rbyh. Almnzmh Al'rbyh Lltrbyh Walthqafh Wal'lwm. Alkwyt.

13. Alemam Ahmd, Ahmd Bn Mhmd Bn Hnbl Alshybany (2001 W1995). Msnd Alemam Ahmd Bn Hnbl. T. M'ssT Alrsalh. W T. Dar Alhdyth. Alqahrh.

14. Abn Aby Hatm, 'bd Alrhmn Bn Mhmd Bn Edrys Bn Almndr (1952). Aljrh Walt'dyl. T. Dar Ehya' Altrath Al'rby. Byrwt.

15. Abn Hban, Mhmd Bn Hban Bn Ahmd Albusty (1965). Althqat. T. Dar Alfkr.

16. Abn Hban, Mhmd Bn Hban Bn Ahmd Albusty (1417h). Alsyrh Alnbwyh Wakhbar Alkhlfa'. T3. Alktb Althqafyh, Byrwt.

17. Abn Hjr, Ahmd Abn Hjr Al'sqlany (Bdwn Tarykh). Thdyb Althdyb. T. Mjls Da'rt Alm'arf Alnzamyh. Alhnd.

18. Abn Hjr, Ahmd Bn 'ly Bn Mhmd Bn Ahmd (2002). Lsan Almyzan. T. Dar Albsha'r Aleslamyh.

19. Alhnbly, Mjyr Aldyn Alqady (1973). Alans Aljlyl Btarykh Alqds Walkhlyl. T. Mktbt Almhtsb. 'man.

20. Hmyd Allh, Mhmd (1987). Mjmw't Alwtha'q Alsyasyh Ll'ehd Alnbwy Walkhlafh Alrashdh. Dar Alnfa's. Byrwt.

21. Abn Aljwzy, Jmal Aldyn Abw Alfrj (1995). Almntzm Fy Tarykt Almlwk Walamm. T. Dar Alfkr Llnshr Waltwzy'. Byrwt.

22. Alkhaldy, Wlyd (2000). Alqds Mn Al'hdh Al'mryh Ela Kamb Dyfd Althanyh. T. M'sst Aldrasat Alflstynyh. Byrwt, Lbnan.

23. Abn Khldwn, 'bd Alrhmn Bn Mhmd Bn Mhmd (2000). Tarykh Abn Khldwn, Almsma Dywan Almbtda Walkhbr Fy Tarykh Al'rb Walbrbr Wmn 'asrhm Mn Dwy Alshan Alakbr. T. Dar Alfkr Lltba'h W Alnshr. Byrwt. Lbnan.

24. Alkhtyb, Rwhy (1970). Thwyd Alqds Alawl Walthany. Bdwn Dar Nshr. 'man.

25. Abn Khyat, Khlyfh Al'sfry (1397h). Tarykh Khlyfh Bn Khyat. T2. Dar Alqlm. Dmshq. Wm'sst Alrsalh. Byrwt.

26. Alraghb Alasfhany, Alhsyn Bn Mhmd (1412h). Almfrdat Fy Ghryb Alqran. T. Dar Alqlm. Aldar Alshamyh. Dmshq. Wbyrwt.

27. Rashd, Syd Frj (1986). Alqds 'rbyh Eslamyh. T. Dar Almrykh Llnshr Waltwzy'. Alryad. Als'wdyh.

28. Alrazy, Mhmd Bn Aby Bkr (1995). Mkhtar Alshah. T. Mktbh Lbnan Nashrwn. Byrwt.

29. Abn Rjb, Zyn Aldyn 'bd Alrhmn Bn Ahmd Bn Alhsn (1996). Fth Albary Shrh Shyh Albkhary. T. Mktbt Alghrba' Alathryh. Almdynh Alnbwyh.

30. Alzyan, Rmdan Eshaq (2006). Rwayat Al'hdh Al'mryh - Drash Twthyqyh. Mjlt Aljam'h Aleslamyh Bghzh: (Slslt Aldrasat Aleslamyh): 14(2): 169-203. 